\title{
An Estimated DSGE Model of the Indian Economy
}

Vasco Gabriel

Paul Levine

Joseph Pearlman

Bo Yang

Working Paper No. 2011-95

November 2011

National Institute of Public Finance and Policy New Delhi http://www.nipfp.org.in 


\title{
An Estimated DSGE Model of the Indian Economy
}

\author{
Vasco Gabriel \\ Paul Levine \\ Joseph Pearlman \\ Bo Yang
}




\title{
An Estimated DSGE Model of the Indian Economy*
}

\author{
VASCO Gabriel \\ PAul Levine \\ UNIVERSITY OF SURREY \\ UNIVERSITY OF SURREY \\ Joseph Pearlman \\ LONDON METROPOLITAN UNIVERSITy \\ BO YANG \\ University of SurRey and London Metropolitan University
}

August 2010

\begin{abstract}
We develop a closed-economy DSGE model of the Indian economy and estimate it by Bayesian Maximum Likelihood methods using Dynare. We build up in stages to a model with a number of features important for emerging economies in general and the Indian economy in particular: a large proportion of credit-constrained consumers, a financial accelerator facing domestic firms seeking to finance their investment, and an informal sector. The simulation properties of the estimated model are examined under a generalized inflation targeting Taylor-type interest rate rule with forward and backward-looking components. We find that, in terms of model posterior probabilities and standard moments criteria, inclusion of the above financial frictions and an informal sector significantly improves the model fit.
\end{abstract}

JEL Classification: E52, E37, E58

Keywords: Indian economy, DSGE model, Bayesian estimation, monetary interest rate rules, financial frictions.

${ }^{*}$ We acknowledge financial support for this research from the Foreign Commonwealth Office as a contribution to the project "Building Capacity and Consensus for Monetary and Financial Reform" led by the National Institute for Public Finance Policy (NIPFP). The paper has benefited from excellent research assistance provided by Rudrani Bhattachrya and Radhika Pandey, NIPFP. 


\section{Contents}

1 Introduction 1

2 A Standard NK Model 3

2.1 The $\mathrm{RBC}$ Core . . . . . . . . . . . . . . . . . . . 3

2.2 From $\mathrm{RBC}$ to $\mathrm{NK} \ldots \ldots \ldots \ldots \ldots$

2.3 The Central Bank . . . . . . . . . . . . . . . . . . 8

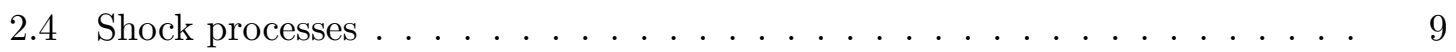

2.5 Bayesian Estimation for US and India . . . . . . . . . . . . . . . 9

2.5.1 Bayesian Methods . . . . . . . . . . . . . . . 10

2.5.2 Data, Priors and Calibration _. . . . . . . . . . . 10

2.5 .3 Posterior Estimates _ . . . . . . . . . . . . . . . . . 12

3 A NK Model with Financial Frictions $\quad 14$

3.1 Bayesian Estimation for India . . . . . . . . . . . . . . . . . 16

4 A Two-Sector NK Model with an Informal Sector 17

4.1 Dynamic Model . . . . . . . . . . . . . . . . . . . . . . . 17

4.2 Bayesian Estimation for India . . . . . . . . . . . . . . . . 20

5 Empirical Applications $\quad 22$

5.1 Further Model Validation . . . . . . . . . . . . . . . . . . . . . . . . . 22

5.2 Standard Moment Criteria . . . . . . . . . . . . . . . . . . . . 23

5.3 Unconditional Autocorrelations . . . . . . . . . . . . . . . . . . . . . 24

5.4 Variance Decomposition of Business Cycle Fluctuations . . . . . . . . . 25

5.5 Posterior Impulse Response Analysis . . . . . . . . . . . . . . . . . . . . . 26

6 Discussion and Future Developments: Open Economy and Policy 29

A Summary of One-Sector Model $\quad 34$

A.1 Dynamic Model . . . . . . . . . . . . . . . . . . . . . . . 34

A.2 Steady State . . . . . . . . . . . . . . . . . . 35

B Summary of two-Sector Model $\quad 36$

B.1 Dynamic Model . . . . . . . . . . . . . . . . . . . . . . 36

B.2 Steady State . . . . . . . . . . . . . . . . . . . 38

C Tables and Figures $\quad 42$ 


\section{INTRODUCTION}

In this chapter, we study the business cycle dynamics of the Indian economy through the lenses of the New Keynesian DGSE framework, both from a theoretical and an empirical perspective. We develop a closed-economy DSGE model of the Indian economy and estimate it by Bayesian Maximum Likelihood methods using Dynare. We build up in stages to a model with a number of features important for emerging economies in general and the Indian economy in particular: a large proportion of credit-constrained consumers, a financial accelerator facing domestic firms seeking to finance their investment and an informal sector. The simulation properties of the estimated model are then examined under a generalized inflation targeting Taylor-type interest rate rule with forward and backward-looking components.

Understanding business cycle fluctuations is at the core of macroeconomics research. The need for models that capture the main features of economic activity and help assessing the role of economic policies has been recognized since the Keynesian tradition of the 50s and 60s. Though the Lucas critique has exposed some of the early flaws of macroeconomic modelling in the 70s, recent developments in the macro literature have led to a breed of dynamic stochastic general equilibrium (DGSE) models that are micro-founded, display consistent expectations-formation mechanisms, can be readily estimated and are therefore appropriate to explain business cycle dynamics from a structural perspective.

The use of DSGE models to analyze business cycles was championed by Kydland and Prescott (1982), who found that a real business cycle (RBC) model with exogenous technology shocks helps explaining a significant portion of the fluctuations in the US economy. Much of the research in this area has, since then, attempted to uncover and understand other potential sources of business cycle fluctuations. This led to several extensions to the basic Kydland-Prescott RBC model, both in the form of additional, different shocks and nominal frictions, the latter introducing a (new) Keynesian flavour to the RBC approach. ${ }^{1}$

Indeed, there is a substantial body of literature devoted to understanding business cycle dynamics in developed economies, where DSGE models have been found to provide good empirical fit and forecasting performance (see Christiano et al. (2005), Smets and Wouters (2003) and Smets and Wouters (2007), among others). However, research focusing on emerging economies is relatively sparser. Data limitations have often been identified as a cause, but the real challenge is to provide sensible explanations for the markedly distinct observed fluctuations in these economies.

In fact, some stylized facts may be pointed out: $i$ ) output growth tends to be subject to larger swings in developing countries; $i i)$ private consumption, relative to income, is substantially more volatile; $i$ ii) terms of trade and output are strongly positively correlated, while real interest rates and output/net exports display large countercyclicality relative to

\footnotetext{
${ }^{1}$ Thus Christiano and Eichenbaum (1992) add demand shocks to the standard RBC model, Carlstrom and Fuerst (1997) and Bernanke et al. (1999) allow for financial frictions, while Christiano et al. (2005) include nominal rigidities, just to name a few contributions.
} 
developed economies; $i v$ ) capital inflows are subject to dramatic "sudden stops" (see Agenor et al. (2000), Aguiar and Gopinath (2007) and Neumeyer and Perri (2005), for example).

By sharing some of these characteristics, India provides a particularly interesting challenge for macroeconomic modelling. From the early 90s, high growth rates were accompanied by a significant wave of trade and financial liberalization, with high-growth and highly-skilled services and exports sectors co-existing with a sizeable informal, low-skilled labour intensive sector. Given the stage of development of India's financial sector, frictions of this nature, affecting both firms and households, may be greatly exacerbated in adverse conditions. Such a scenario implies that policymakers, in their quest for price and financial stability, face extra significant trade-offs when setting monetary conditions in response to shocks. This, in turn, requires careful investigation of the mechanisms that contribute to the propagation and amplification of economic and financial shocks hitting the economy.

This study aims to integrate some of these distinct features within a framework that provides a convenient way of taking the models to the data. First, we introduce a standard DSGE model with typical New Keynesian frictions, in the form of imperfect competition, sticky prices and investment adjustment costs. We show how to augment the baseline model with additional frictions in order to reflect the characteristics of the Indian economy. In particular, we explore the presence of financial frictions in the form of a financial accelerator mechanism as in Bernanke et al. (1999) and liquidity constrained consumers. Moreover, we further develop the model by allowing for the existence of a formal and a less capital-intensive informal sector, producing distinct goods with different technologies sold at different prices. This phenomenon is particularly important in emerging economies, given their high degrees of informal labour and financial services and the implications these have for the effectiveness of macroeconomic policy (see Batini et al. (2010b) for a recent survey).

Then, using data on four key macroeconomic variables (output, investment, inflation and interest rates), we first explore the differences in business cycle dynamics between a developed economy (the US) and India, as captured by the baseline New Keynesian DSGE model. We subsequently investigate the empirical success of the competing models in explaining the main stylized facts of the Indian business cycle. We do so by employing Bayesian system estimation techniques, in the vein of Smets and Wouters (2003), Smets and Wouters (2007) and Fernandez-Villaverde and Rubio-Ramirez (2004) (for a survey, see Fernandez-Villaverde, 2009). To our knowledge, this is the first study that estimates a model with a formal-informal sectors distinction.

We take a Bayesian approach for several reasons. First, these procedures, unlike full information maximum likelihood, for example, allow us to use prior information to identify key structural parameters. In addition, the Bayesian methods employed here utilize all the cross-equation restrictions implied by the general equilibrium set-up, which makes estimation more efficient when compared to the partial equilibrium approaches. Moreover, Bayesian estimation and model comparison are consistent even when the models are 
misspecified, as shown by Fernandez-Villaverde and Rubio-Ramirez (2004). ${ }^{2}$ Finally, this framework provides a straightforward method of evaluating the ability of the models in capturing the cyclical features of the data, while allowing for a fully structural approach to analyse the sources of fluctuations in the Indian economy.

We find that a model incorporating financial frictions and a formal-informal sector distinction fits the data well and delivers sensible structural parameter estimates. This, in our opinion, should constitute the first step in the construction of models suitable for the systematic analysis of policy actions.

Indeed, the role of fiscal policy cannot be properly understood, discussed and assessed unless these specific features, of which we provide a basic framework, are taken into account. Concurrently, monetary policy in India is difficult to encapsulate in conventional policy rules, given the broad scope of the Reserve Bank of India's (RBI) mandate (controlling inflation, managing pressures on the exchange rate and coping with capital flows). We discuss how a generalized policy rule can be used to capture (and evaluate) the RBI stance, our results suggesting that India's monetary authority policy actions appear to aggressively target expected inflation, albeit at a short term horizon.

Thus, in the next section, we describe a baseline New Keynesian DSGE and estimate it with US and Indian data, illustrating the differences between these two economies. In section 3 , we introduce liquidity constrained consumers and a financial accelerator mechanism into the baseline model. Then, in section 4, we develop a two-sector model allowing for informality and compare the empirical performance of the competing models. The final section summarizes our findings and points directions for further study.

\section{A Standard NK Model}

This section develops a standard New Keynesian (NK) DSGE model without any features we associate with emerging economies. To give us a preliminary insight into what is different about an emerging economy such as India, this benchmark model is then estimated by Bayesian methods using both Indian and US data.

\subsection{The RBC CORE}

Every NK DSGE model has at its core a real business cycle model, describing the intertemporal problems facing consumers and firms and defining what would happen in the absence of the various Keynesian frictions. We first define a single-period utility for the representative agent in terms of consumption, $C_{t}$, and leisure, $L_{t}$, as

$$
\Lambda_{t}=\Lambda\left(C_{t}, L_{t}\right)=\frac{\left(C_{t}^{(1-\varrho)} L_{t}^{\varrho}\right)^{1-\sigma}-1}{1-\sigma}
$$

\footnotetext{
${ }^{2}$ This is an important methodological point, given that the models discussed in this paper, by focusing only on the closed economy and therefore omitting open economy features, are inherently 'misspecified'.
} 
In this utility function $\sigma \geq 1$ is a risk-aversion parameter which is also the inverse of the inter-temporal rate of substitution. The parameter $\varrho \in(0,1)$ defines the relative weight households place on consumption and this form of utility is compatible with a balanced growth steady state for for all $\sigma \geq 1 .^{3}$ For later use, we write down the marginal utilities of consumption and leisure as, respectively,

$$
\begin{aligned}
& \Lambda_{C, t}=(1-\varrho) C_{t}^{(1-\varrho)(1-\sigma)-1} L_{t}^{\varrho(1-\sigma)} \\
& \Lambda_{L, t}=\varrho C_{t}^{(1-\varrho)(1-\sigma)} L_{t}^{\varrho(1-\sigma)-1}
\end{aligned}
$$

The value function at time $t$ of the representative household is given by

$$
\Omega_{t}=E_{t}\left[\sum_{s=0}^{\infty} \beta^{s} \Lambda\left(C_{t+s}, L_{t+s}\right)\right]
$$

where $\beta$ is the discount factor. In a stochastic environment, the household's problem at time $t$ is to choose state-contingent plans for consumption $\left\{C_{t}\right\}$, leisure, $\left\{L_{t}\right\}$ and holdings of financial savings to maximize $\Omega_{t}$ given its budget constraint in period $t$

$$
B_{t+1}=B_{t}\left(1+R_{t}\right)+W_{t} h_{t}-C_{t}
$$

where $B_{t}$ is the net stock of real financial assets at the beginning of period $t, W_{t}$ is the real wage rate and $R_{t}$ is the real interest rate paid on assets held at the beginning of period $t$. Hours worked are $h_{t}=1-L_{t}$ and the total amount of time available for work or leisure is normalized at unity. The first-order conditions for this optimization problem are

$$
\begin{aligned}
\Lambda_{C, t} & =\beta E_{t}\left[\left(1+R_{t+1}\right) \Lambda_{C, t+1}\right] \\
\frac{\Lambda_{L, t}}{\Lambda_{C, t}} & =W_{t}
\end{aligned}
$$

Equation (6) is the Euler consumption function: it equates the current marginal utility of consumption with the discounted marginal of consumption of a basket of goods in period $t+1$ enhanced by the interest on savings. Thus, the household is indifferent as between consuming 1 unit of income today or $1+R_{t+1}$ units in the next period. Equation (7) equates the marginal rate of substitution between consumption and leisure with the real wage, the relative price of leisure. This completes the household component of the RBC model.

Turning to the production side, we assume that output $Y_{t}$ is produced by the representative competitive firm using hours, $h_{t}$ and beginning-of-period capital $K_{t}$ with a Cobb-Douglas production function

$$
Y_{t}=F\left(A_{t}, h_{t}, K_{t}\right)=\left(A_{t} h_{t}\right)^{\alpha} K_{t}^{1-\alpha}
$$

\footnotetext{
${ }^{3}$ See Barro and Sala-i-Martin (2004), chapter 9.
} 
where $A_{t}$ is a technology parameter and $Y_{t}, h_{t}$ and $K_{t}$ are all in per-capita (household) units. Assume first that capital can adjust instantly without investment costs. Then equating the marginal product of labour with the real wage and the marginal product of capital with its the cost (given by the real interest rate plus the depreciation rate, $R_{t}+\delta$ ), we have: ${ }^{4}$

$$
\begin{aligned}
F_{h, t} & =\alpha \frac{Y_{t}}{h_{t}}=W_{t} \\
F_{K, t} & =(1-\alpha) \frac{Y_{t}}{K_{t}}=R_{t}+\delta
\end{aligned}
$$

Let investment in period $t$ be $I_{t}$. Then capital accumulates according to

$$
K_{t+1}=(1-\delta) K_{t}+I_{t}
$$

The RBC model is then completed with an output equilibrium equating supply and demand

$$
Y_{t}=C_{t}+I_{t}+G_{t}
$$

where $G_{t}$ is government spending on services assumed to be formed out of the economy's single good and by a financial market equilibrium. In this model, the only asset accumulated by households as a whole is capital, so the latter equilibrium is simply $B_{t}=K_{t}$. Substituting into the household budget constraint (5) and using the first-order conditions (9) and (10), and (11) we end up with the output equilibrium condition (12). In other words, equilibrium in the two factor markets and the output market implies equilibrium in the remaining financial market, which is simply a statement of Walras' Law.

Now let us introduce investment costs. It is convenient for the later development of the model to introduce capital producing firms that at time $t$ convert $I_{t}$ of output into $\left(1-S\left(X_{t}\right)\right) I_{t}$ of new capital sold at a real price $Q_{t}$ and at a cost (that was absent before) of $S\left(X_{t}\right)$. Here, $X_{t} \equiv \frac{I_{t}}{I_{t-1}}$ and the function $S(\cdot)$ satisfies $S^{\prime}, S^{\prime \prime} \geq 0 ; S(1+g)=S^{\prime}(1+g)=0$ where $g$ is the balanced-path growth rate. Thus, investment costs are convex and disappear along in the balanced growth steady state. They then maximize expected discounted profits

$$
E_{t} \sum_{k=0}^{\infty} D_{t, t+k}\left[Q_{t+k}\left(1-S\left(I_{t+k} / I_{t+k-1}\right)\right) I_{t+k}-I_{t+k}\right]
$$

where $D_{t, t+k} \equiv \beta \frac{\Lambda_{C, t+k}}{\Lambda_{C, t}}$ is the real stochastic discount rate and

$$
K_{t+1}=(1-\delta) K_{t}+\left(1-S\left(X_{t}\right)\right) I_{t}
$$

This results in the first-order condition

$$
Q_{t}\left(1-S\left(X_{t}\right)-X_{t} S^{\prime}\left(X_{t}\right)\right)+E_{t}\left[D_{t, t+1} Q_{t+1} S^{\prime}\left(X_{t+1}\right) \frac{I_{t+1}^{2}}{I_{t}^{2}}\right]=1
$$

\footnotetext{
${ }^{4}$ Thus $Y_{t}=W_{t} h_{t}+\left(R_{t}+\delta\right)$, the zero-profit condition for the competitive firm.
} 
Demand for capital by firms must satisfy

$$
E_{t}\left[\left(1+R_{t+1}\right) R P S_{t+1}\right]=\frac{E_{t}\left[(1-\alpha) \frac{P_{t+1}^{W} Y_{t+1}}{K_{t+1}}+(1-\delta) Q_{t+1}\right]}{Q_{t}}
$$

In (15) the right-hand-side is the gross return to holding a unit of capital in from $t$ to $t+1$. The left-hand-side is the gross return from holding bonds, the opportunity cost of capital and includes an exogenous risk-premium shock $R P S_{t}$, which, for now, we leave unmodelled. We complete the set-up with investment costs by defining the functional form

$$
S(X)=\phi_{X}\left(X_{t}-(1+g)\right)^{2}
$$

The RBC model we have set out defines a equilibrium in output, $Y_{t}$, consumption $C_{t}$, investment $I_{t}$, capital stock $K_{t}$ and factor prices, $W_{t}$ for labour and $R_{t}$ for capital, and the price of capital $Q_{t}$, given exogenous processes for technology $A_{t}$, government spending $G_{t}$ and the risk premium shock $R P S_{t}$.

\subsection{From RBC TO NK}

The NK framework combines the DSGE characteristics of RBC models with frictions such as monopolistic competition - in which firms produce differentiated goods and are price-setters, instead of a Walrasian determination of prices, and nominal rigidities, in which firms face constraints on the frequency with which they are able to adjust their prices. Therefore, we now introduce a monopolistically competitive retail sector that uses a homogeneous wholesale good to produce a basket of differentiated goods for consumption

$$
C_{t}=\left(\int_{0}^{1} C_{t}(m)^{(\zeta-1) / \zeta} d m\right)^{\zeta /(\zeta-1)}
$$

where $\zeta$ is the elasticity of substitution. This implies a set of demand equations for each intermediate good $m$ with price $P_{t}(m)$ of the form

$$
C_{t}(m)=\left(\frac{P_{t}(m)}{P_{t}}\right)^{-\zeta} C_{t}
$$

where $P_{t}=\left[\int_{0}^{1} P_{t}(m)^{1-\zeta} d m\right]^{\frac{1}{1-\zeta}}$ is the aggregate price index. A competitive capitalproducing sector is modelled as for the RBC model

Conversion of good $m$ from a homogeneous output requires a cost $c Y_{t}^{W}(m)$ where wholesale production uses the production technology (8). Thus

$$
\begin{aligned}
Y_{t}(m) & =(1-c) Y_{t}^{W}(m) \\
Y_{t}^{W} & =\left(A_{t} h_{t}\right)^{\alpha} K_{t}^{1-\alpha}
\end{aligned}
$$


To introduce price stickiness, we assume that there is a probability of $1-\xi$ at each period that the price of each intermediate good $m$ is set optimally to $P_{t}^{0}(m)$. If the price is not re-optimized, then it is held fixed. ${ }^{5}$ For each intermediate producer $m$, the objective is at time $t$ to choose $\left\{P_{t}^{0}(m)\right\}$ to maximize discounted profits

$$
E_{t} \sum_{k=0}^{\infty} \xi^{k} D_{t, t+k} Y_{t+k}(m)\left[P_{t}^{0}(m)-P_{t+k} M C_{t+k}\right]
$$

subject to (18), where $D_{t, t+k}$ is now the nominal stochastic discount factor over the interval $[t, t+k]$. The solution to this is

$$
E_{t} \sum_{k=0}^{\infty} \xi^{k} D_{t, t+k} Y_{t+k}(m)\left[P_{t}^{0}(m)-\frac{1}{(1-1 / \zeta)} P_{t+k} M C_{t+k} M S_{t+k}\right]=0
$$

In (22) we have introduced a mark-up shock $M S_{t}$ to the steady state mark-up $\frac{1}{(1-1 / \zeta)}$. By the law of large numbers, the evolution of the price index is given by

$$
P_{t+1}^{1-\zeta}=\xi P_{t}^{1-\zeta}+(1-\xi)\left(P_{t+1}^{0}\right)^{1-\zeta}
$$

In setting up the model for simulation and estimation, it is useful to represent the price dynamics as difference equations. Using the fact that for any summation $S_{t} \equiv$ $\sum_{k=0}^{\infty} \beta^{k} X_{t+k}$, we can write

$$
\begin{aligned}
S_{t} & =X_{t}+\sum_{k=1}^{\infty} \beta^{k} X_{t+k}=X_{t}+\sum_{k^{\prime}=0}^{\infty} \beta^{k^{\prime}+1} X_{t+k^{\prime}+1} \text { putting } k^{\prime}=k+1 \\
& =X_{t}+\beta S_{t+1}
\end{aligned}
$$

and defining here the nominal discount factor by $D_{t, t+k} \equiv \beta \frac{\Lambda_{C, t+k} / P_{t+k}}{\Lambda_{C, t} / P_{t}}$, inflation dynamics are given by

$$
\begin{aligned}
H_{t}-\xi \beta E_{t}\left[\Pi_{t+1}^{\zeta-1} H_{t+1}\right] & =Y_{t} \Lambda_{C, t} \\
J_{t}-\xi \beta E_{t}\left[\Pi_{t+1}^{\zeta} J_{t+1}\right] & =\left(\frac{1}{1-\frac{1}{\zeta}}\right) Y_{t} \Lambda_{C, t} M C_{t} M S_{t} \\
1 & =\xi \Pi_{t}^{\zeta-1}+(1-\xi)\left(\frac{J_{t}}{H_{t}}\right)^{1-\zeta}
\end{aligned}
$$

Real marginal costs are no longer fixed and are given by

$$
M C_{t}=\frac{P_{t}^{W}}{P_{t}}
$$

\footnotetext{
${ }^{5}$ Thus we can interpret $\frac{1}{1-\xi}$ as the average duration for which prices are left unchanged.
} 


\subsection{The Central Bank}

Following the current practice of central banks in developed economies, it is customary to assume that setting the nominal interest rate is the main instrument of monetary policy and, hence, this is modelled by some form of interest rate rule. Nominal and real interest rates are related by the Fischer equation

$$
E_{t}\left[1+R_{t+1}\right]=E_{t}\left[\frac{1+R_{n, t}}{\Pi_{t+1}}\right]
$$

where the nominal interest rate $R_{n, t}$, set at the beginning of period $t$, is a policy variable, typically given in the literature by a simple Taylor-type rule:

$$
\log \left(\frac{1+R_{n, t}}{1+R_{n}}\right)=\rho \log \left(\frac{1+R_{n, t-1}}{1+R_{n}}\right)+\theta \log \left(\frac{\Pi_{t}}{\Pi}\right)
$$

As mentioned in the introduction, that is not necessarily the case of the RBI. In fact, we will model monetary policy in a more general way by formulating a Calvo-type forwardbackward interest rate rule as in Levine et al. (2007) and Gabriel et al. (2009). This is defined by

$$
\log \left(\frac{1+R_{n, t}}{1+R_{n}}\right)=\rho \log \left(\frac{1+R_{n, t-1}}{1+R_{n}}\right)+\theta \log \frac{\Theta_{t}}{\Theta}+\phi \log \frac{\Phi_{t}}{\Phi}+\epsilon_{M P S, t}
$$

where $\epsilon_{M P S, t}$ is a monetary policy shock and

$$
\begin{aligned}
\log \Phi_{t} & =\log \Pi_{t}+\tau \log \Phi_{t-1} \\
\varphi E_{t}\left[\log \Theta_{t+1}\right] & =\log \Theta_{t}-(1-\varphi) \log \left(\Pi_{t}\right)
\end{aligned}
$$

The Calvo rule can be interpreted as a feedback from expected inflation (the $\theta \log \frac{\Theta_{t}}{\Theta}$ term) and past inflation (the $\phi \log \frac{\Phi_{t}}{\Phi}$ term) that continues at any one period with probabilities $\varphi$ and $\tau$, switching off with probabilities $1-\varphi$ and $1-\tau$. The probability of the rule lasting for $h$ periods is $(1-\varphi) \varphi^{h}$, hence the mean forecast horizon is $(1-\varphi) \sum_{h=1}^{\infty} h \varphi^{h}=$ $\varphi /(1-\varphi)$. With $\varphi=0.5$, for example, we would have a Taylor rule with one period lead in inflation $(h=1)$. Similarly, $\tau$ can be interpreted as the degree of backward-lookingness of the monetary authority.

This rule can also be seen as a special case of a Taylor-type rule that targets $h$-step-ahead (back) expected rates of inflation and past inflation rates (with $h=1,2, \ldots, \infty)$

$$
i_{t}=\rho i_{t-1}+\theta_{0} \pi_{t}+\theta_{1} E_{t} \pi_{t+1}+\theta_{2} E_{t} \pi_{t+2}+\ldots+\gamma_{1} \pi_{t-1}+\gamma_{2} \pi_{t-2}+\ldots
$$

albeit one that imposes a specific structure on the $\theta_{i}$ 's and $\gamma_{i}$ 's (i.e., a weighted average of future and past variables with geometrically declining weights). ${ }^{6}$ This has an intuitive appeal

\footnotetext{
${ }^{6} i_{t}$ and $\pi_{t}$ correspond to $\log \left(\frac{1+R_{n, t}}{1+R_{n}}\right)$ and $\log \left(\frac{\Pi_{t}}{\Pi}\right)$, to simplify notation.
} 
and interpretation, reflecting monetary policy in an uncertain environment: the more distant the $h$-step ahead forecast, the less reliable it becomes, hence the less weight it receives. In turn, past inflation has a typical Koyck-lag structure. Levine et al. (2007) demonstrate that a strict inflation forecast based (IFB) Calvo rule is less susceptible to indeterminacy and has better stabilization properties than conventional IFB rules. These authors show, in particular, that if such rule is formulated in difference form, the indeterminacy probem disappears altogether.

Note that we are approximating the behaviour of the central bank with an instrument rule, rather than assuming that the monetary authority optimizes a specific loss function. Despite the lack of a substantial body of evidence for the Indian case, the forward-backwardlooking Calvo-type formulation can be useful to analyse the RBI's interest rate setting behaviour. Bhattacharya et al. (2010), using VAR methods, find monetary policy in India to have weak transmission channels. On the other hand, however, Virmani (2004) reports on the potential forward/backward looking behaviour of the RBI using instrumental rules, suggesting that a backward-looking rule explains the data well. Our proposal nests both types of behaviour and can therefore shed light on their relative importance.

\subsection{SHOCK PROCESSES}

The structural shock processes in log-linearized form are assumed to follow AR(1) processes

$$
\begin{aligned}
\log A_{t}-\log \bar{A}_{t} & =\rho_{A}\left(\log A_{t-1}-\log \bar{A}_{t-1}\right)+\epsilon_{A, t} \\
\log G_{t}-\log \bar{G}_{t} & =\rho_{G}\left(\log G_{t-1}-\log \bar{G}_{t-1}\right)+\epsilon_{G, t} \\
\log M S_{t}-\log M S & =\rho_{M S}\left(\log M S_{t-1}-\log M S\right)+\epsilon_{M S, t} \\
\log R P S_{t}-\log R P S & =\rho_{R P S}\left(\log R P S_{t-1}-\log R P S\right)+\epsilon_{R P S, t}
\end{aligned}
$$

where $M S=R P S=1$ in the steady state ( $\operatorname{so} \log M S=\log R P S=0$ ), while the driving shocks $\epsilon_{i, t}$ for $i=\mathrm{A}, \mathrm{G}, \mathrm{MS}, \mathrm{RPS}$ are assumed to be i.i.d. with zero mean. $\bar{A}_{t}$ and $\bar{G}_{t}$ are balanced-growth paths at a growth rate $g$ with $\frac{\bar{G}_{t}}{Y_{t}}$ fixed. This completes the specification of the benchmark NK model.

\subsection{BAYESIAN ESTIMATION FOR US AND INDIA}

We now present estimates of the model discussed above for the US and the Indian economies. This exercise allows us: $i$ ) to evaluate how well a baseline New Keynesian DSGE model fits Indian data, and $i i$ ) to highlight some of the distinctive traits between a much studied developed economy and India. For estimation purposes we linearize about a zero inflation balanced growth steady state. This is set out for the more general model of section 3 with financial frictions which reduces to the standard model of this section when the latter are removed. Next, we briefly describe the estimation methods used in this chapter. 


\subsubsection{Bayesian Methods}

Bayesian estimation entails obtaining the posterior distribution of the model's parameters, say $\theta$, conditional on the data. Using the Bayes' theorem, the posterior distribution is obtained as:

$$
p\left(\theta \mid Y^{T}\right)=\frac{L\left(Y^{T} \mid \theta\right) p(\theta)}{\int L\left(Y^{T} \mid \theta\right) p(\theta) d \theta}
$$

where $p(\theta)$ denotes the prior density of the parameter vector $\theta, L\left(Y^{T} \mid \theta /\right)$ is the likelihood of the sample $Y^{T}$ with $T$ observations (evaluated with the Kalman filter) and $\int L\left(Y^{T} \mid \theta\right) p(\theta)$ is the marginal likelihood. Since there is no closed form analytical expression for the posterior, this must be simulated.

One of the main advantages of adopting a Bayesian approach is that it facilitates a formal comparison of different models through their posterior marginal likelihoods, computed using the Geweke (1999) modified harmonic-mean estimator. For a given model $m_{i} \in M$ and common data set, the marginal likelihood is obtained by integrating out vector $\theta$,

$$
L\left(Y^{T} \mid m_{i}\right)=\int_{\Theta} L\left(Y^{T} \mid \theta, m_{i}\right) p\left(\theta \mid m_{i}\right) d \theta
$$

where $p_{i}\left(\theta \mid m_{i}\right)$ is the prior density for model $m_{i}$, and $L\left(Y^{T} \mid m_{i}\right)$ is the data density for model $m_{i}$ given parameter vector $\theta$. To compare models (say, $m_{i}$ and $m_{j}$ ) we calculate the posterior odds ratio which is the ratio of their posterior model probabilities (or Bayes Factor when the prior odds ratio, $\frac{p\left(m_{i}\right)}{p\left(m_{j}\right)}$, is set to unity):

$$
\begin{aligned}
P O_{i, j} & =\frac{p\left(m_{i} \mid Y^{T}\right)}{p\left(m_{j} \mid Y^{T}\right)}=\frac{L\left(Y^{T} \mid m_{i}\right) p\left(m_{i}\right)}{L\left(Y^{T} \mid m_{j}\right) p\left(m_{j}\right)} \\
B F_{i, j} & =\frac{L\left(Y^{T} \mid m_{i}\right)}{L\left(Y^{T} \mid m_{j}\right)}=\frac{\exp \left(L L\left(Y^{T} \mid m_{i}\right)\right)}{\exp \left(L L\left(Y^{T} \mid m_{j}\right)\right)}
\end{aligned}
$$

in terms of the log-likelihoods. Components (37) and (38) provide a framework for comparing alternative and potentially misspecified models based on their marginal likelihood. Such comparisons are important in the assessment of rival models, as the model which attains the highest odds outperforms its rivals and is therefore favoured.

Given Bayes factors, we can easily compute the model probabilities $p_{1}, p_{2}, \cdots, p_{n}$ for $n$ models. Since $\sum_{i=1}^{n} p_{i}=1$ we have that $\frac{1}{p_{1}}=\sum_{i=2}^{n} B F_{i, 1}$, from which $p_{1}$ is obtained. Then $p_{i}=p_{1} B F(i, 1)$ gives the remaining model probabilities.

\subsubsection{Data, Priors and Calibration}

To estimate the system for each economy, we use four macroeconomic observables at quarterly frequency. For the US, we use real GDP, real investment, the GDP deflator and the nominal interest rate. All data are taken from the FRED Database available through the Federal Reserve Bank of St.Louis and the sample period is 1980:1-2006:4. We use the 
corresponding four observables for the Indian economy, covering the period from the first quarter of 1996 and the last quarter of 2008 and taken from the IFS and RBI database. The inflation rate is calculated on the Wholesale Price Index (WPI), which includes food, fuel and manufacturing indices. The interest rate is measured by the 91-day Treasury Bill rate, in order to capture the combined effect of the RBI policy rates and liquidity changes brought about by the Bank sterilization interventions (see Bhattacharya et al. (2010)). A time series for investment is only available at the annual frequency. Thus, we use the interpolation techniques suggested by Litterman (1983) to obtain quarterly data based on the Index of Industrial Production (IIP) for capital goods. ${ }^{7}$ For GDP, data is available from 1996:4 onwards, so we interpolate the first few initial periods from annual data, using the IIP.

Since the variables in the model are measured as deviations from a constant steady state, the US GDP and investment are simply de-trended against a linear trend in order to obtain approximately stationary data. In the case of India, however, a quadratic trend is required to ensure stationarity. ${ }^{8}$ Real variables are measured in logarithmic deviations from the respective trends, in percentage points, while inflation and the nominal interest rate are demeaned and expressed as quarterly rates. The corresponding measurement equation for the US data and model is (for the remaining models, the structure is similar):

$$
\left[\begin{array}{c}
G D P_{t} \\
I N V_{t} \\
\log \left(G D P D E F_{t}-G D P D E F_{t-1}\right) \\
F E D F U N D S_{t} / 4
\end{array}\right]=\left[\begin{array}{c}
\log \left(\frac{Y_{t}}{Y}\right) \\
\log \left(\frac{I_{t}}{I}\right) \\
\log \left(\frac{\Pi_{t}}{\Pi}\right) \\
\log \left(\frac{1+R_{n, t}}{1+R_{n}}\right)
\end{array}\right]
$$

In order to implement Bayesian estimation, it is first necessary to define prior distributions for the parameters. A few structural parameters are kept fixed in the estimation procedure, in accordance with the usual practice in the literature (see Table 1). This is done so that the calibrated parameters reflect steady state values of the observed variables. For the US, we follow Smets and Wouters (2007) in defining the priors for the estimated parameters and calibrated parameters. ${ }^{9}$ In the case of India, for instance, $\beta$ is set at 0.9823 , corresponding to an interest rate of $7 \%$ (matching its sample mean), while $\delta=0.025$ is a common choice for the depreciation rate. In turn, the investment adjustment cost parameter $\phi_{X}$ is set at 2 .

The choice of priors for the estimated parameters is usually determined by the theoretical

\footnotetext{
${ }^{7}$ The Bayesian system estimation techniques used in our study can easily handle variables measured with imprecision, by introducing stochastic measurement errors. Exploratory analysis revealed that measurement errors are a negligible source of uncertainty in our estimated models and we therefore focus on estimation results without measurement errors.

${ }^{8}$ Removing a quadratic trend from the US data or employing the Hodrick-Prescott filter for both countries delivers time series with similar behaviour and estimation results are qualitatively, and quantitatively, very close

${ }^{9}$ The prior means for the standard deviation of government spending and markup shocks are re-scaled based on the differences in model setups.
} 
implications of the model and evidence from previous studies. However, as noted in the introduction, estimated DSGE models for emerging economies, and India in particular, are scarce, though one might infer potential priors by comparing the features and stylized facts of developed and developing economies. In general, inverse gamma distributions are used as priors when non-negativity constraints are necessary, and beta distributions for fractions or probabilities. Normal distributions are used when more informative priors seem to be necessary. In some cases, we use the same prior means as in previous studies (Levin et al. (2006), Smets and Wouters (2003) and Smets and Wouters (2007), for example), but choose larger standard deviations, thus imposing less informative priors and allowing for the data to determine the parameters' location. The first four columns of Table 3 provide an overview of the priors used for each model variant described below in the case of India. For consistency and comparability, all priors are the same across different specifications.

The risk aversion parameter $\sigma$ allows significant room for manoeuvre, with a normal prior defined with a mean of 2 and standard deviation of 0.5 . The beta prior density for $\varrho$ is centred in the midpoint of the unit interval with a standard deviation of 0.2 , while the Calvo-pricing parameter $\xi$ has a mean of 0.75 and standard deviation of 0.1 as in Smets and Wouters (2007), implying a contract length of 4 quarters. The labour share $\alpha$ has a normal prior with mean 0.8 (approximately its steady state value ${ }^{10}$ ), while $\zeta$ has a mean of 7 with a standard deviation of 0.5 .

For the policy parameters, priors were chosen so that a large domain is covered, reflecting the lack of knowledge of the RBI reaction function. We choose beta distributions for the parameters that should be constrained between 0 and 1, namely the smoothing coefficient $\rho$ (centred around 0.75 with a standard deviation of 0.1 ) and the forward-backward looking parameters $\varphi$ and $\tau$, with a mean of 0.5 and a standard deviation of 0.2 , a relatively diffuse prior. The feedback parameters $\theta$ and $\phi$ have normal priors with a mean of 2 and a standard error of 1 , thus covering a relatively large parameter space.

The shock processes are the likeliest elements to differ from previous studies based on the US economy. Adolfson et al. (2008), for example, argue for choosing larger prior means for shock processes when analyzing a small open developed economy (Sweden). In the case of India, it is natural to expect significantly larger swings in the macro observables and the prior means for the standard errors are therefore set at 3 (3.5 for the risk premium shock, higher than the US), using an inverted gamma distribution.

\subsubsection{Posterior Estimates}

The joint posterior distribution of the estimated parameters is obtained in two steps. First, the posterior model and the Hessian matrix are obtained via standard numerical optimization routines. The Hessian matrix is then used in the Metropolis-Hastings algorithm to

\footnotetext{
${ }^{10}$ We chose not to calibrate $\alpha$ to its steady state value and instead freely estimate this parameter. The proximity of the estimated values for $\alpha$ will provide additional indications regarding the quality of the fit for each model.
} 
generate a sample from the posterior distribution. Two parallel chains are used in the MCMC-MH algorithm and in all the estimations reported in this paper, the univariate diagnostic statistics produced by Dynare indicate convergence by comparing between and within moments of multiple chains (Brooks and Gelman (1998)).

Thus, 100,000 random draws (though the first 30\% "burn-in" observations are discarded) from the posterior density are obtained via the MCMC-Metropolis Hastings algorithm $(\mathrm{MH})$, with the variance-covariance matrix of the perturbation term in the algorithm being adjusted in order to obtain reasonable acceptance rates (between 20\%-40\%). ${ }^{11}$ The estimation results for the US report the Bayesian inference in Table 2. Table 3, fourth column, reports posterior means of all estimated parameters using the Indian data, along with the approximate $95 \%$ confidence intervals based on the approximate posterior standard deviation obtained from the inverse Hessian at the posterior mode.

As shown in Table 2, the estimation results are plausible and are generally similar to those of Levin et al. (2006) and Smets and Wouters (2007) for the US. In particular, the posterior mean estimates for the Calvo price-setting parameter, $\xi$, imply an average price contract duration of around 2.5 quarters, similar to the findings of Christiano et al. (2005), Levin et al. (2006) and Smets and Wouters (2007). It is interesting to note that the risk-aversion parameter $(\sigma)$ is estimated to be slightly greater than assumed in the prior distribution, indicating that the inter-temporal elasticity of substitution (proportional to $1 / \sigma$ ) is estimated to be about 0.54 in the US, which is plausible as suggested in much of RBC literature. As usual, monetary policy disturbances $\left(\epsilon_{M P S}\right)$ are less important in driving inflation and output in the US.

As expected, the policy rule estimates imply a fairly strong response $(\theta)$ to expected inflation by the US Fed Reserve and the degree of interest rate smoothing $(\rho)$ is fairly strong. Our posterior results also suggest that the point estimates of the policy reaction to past inflation appear small, which is in line with our prior belief. The estimated degree of backward lookingness is well below the prior mean, further suggesting that the practice of the Fed is consistent with a substantial degree of forward-looking behaviour. This reinforces previous findings in the literature, in particular Gabriel et al. (2009).

Turning to the estimates for India, the estimated $\xi$ is well below its prior of 0.75 , suggesting that firms adjust prices quite frequently, between 1 and 3 quarters, and implying only mild price stickiness. Similarly, the estimated model undershoots $\alpha$, suggesting a labour share of $62 \%$. Note, however, that structural parameters like $\sigma$ and $\zeta$ deviate little from their prior means, in fact the posterior distributions overlap with the prior ones, which might suggest that the data is not very informative about these parameters. $\varrho$, on the other hand, is pinned down with better precision at around 0.4.

In terms of the policy parameters, we find a substantial degree of policy inertia, with $\rho$ reaching 0.81. More importantly, the estimated Calvo rule seems to suggests that the RBI sets interest rates reacting strongly to expected inflation (with the feedback coefficient

\footnotetext{
${ }^{11}$ See Schorfheide (2000) for more details.
} 
$\theta$ larger than 1.5), but less so to inflationary pressures associated with past inflation, as captured by $\phi$. However, both $\theta$ and $\phi$ are estimated imprecisely, the latter not being statistically significant. The degree of forward (backward) lookingness measured by $\varphi(\tau)$ is close to the prior value of 0.5 , corresponding to 1 quarter.

Estimation of the shock processes delivers interesting results. First, the shocks appear to be persistent, but less so than for the US. Secondly, the estimated standard deviations are larger than the US, in accordance with the macro volatility stylized facts typically associated with emerging economies. Most strikingly, the standard error associated with the government spending shock reaches a value above 7 , while the risk premium shock standard deviation is also high. The remaining standard deviations are somewhat below the specified priors.

Overall, the estimated baseline model reveals some useful insights: it correctly predicts that the Indian economy is subject to more volatile shocks, prices appear to be more flexible for India than for the in US and that aggressive expected inflation targeting seems to be consistent with the behaviour of the monetary authorities. In the next two sections, we investigate further refinements and assess their empirical validity, providing a more thorough comparison of the different specifications under study.

\section{A NK Model with Financial Frictions}

We now introduce two financial frictions: liquidity constrained 'rule of thumb' consumers and a financial accelerator for firms. The inclusion of these features is particularly relevant, not only because it acknowledges powerful transmission mechanisms of shocks in emerging economies, but it also helps to conceptualize and understand events such as the 2008 global financial crisis and subsequent economic slowdown. Carlstrom and Fuerst (1997), Bernanke et al. (1999) and Gertler et al. (2003), for example, stress the importance of financial frictions in the amplification of both real and nominal shocks to the economy, namely in the form of the financial accelerator, linking the cost of borrowing and firms' net worth.

Consider first the existence of liquidity constrained consumers. Suppose that a proportion $\lambda$ of consumers are credit constrained and have no income from monopolistic retail firms. They must consume out of wage income and their consumption is given by

$$
C_{1, t}=\frac{W_{t} h_{t}}{P_{t}}
$$

The remaining Ricardian consumers are modelled as before and consume $C_{2, t}$. Total consumption is then

$$
C_{t}=\lambda C_{1, t}+(1-\lambda) C_{2, t}
$$

We can model the risk premium rigorously and financial stress by introducing a financial accelerator. The main ingredient is an external finance premium $\Theta_{t}$ such that when the 
firm equates the expected return with the expected cost of borrowing we have

$$
E_{t}\left[1+R_{k, t+1}\right]=E_{t}\left[\Theta_{t+1}\left(1+R_{t+1}\right)\right]
$$

where

$$
\Theta_{t}=k\left(\frac{N_{t}}{Q_{t-1} K_{t}}\right)^{-\chi}
$$

is our chosen functional form. In (43), $N_{t}$ is net worth and $Q_{t-1} K_{t}-N_{t}$ is the external financing requirement. Thus $\frac{Q_{t-1} K_{t}-N_{t}}{N_{t}}$ is the leverage ratio and thus (42) and (43) state that the cost of capital is an increasing function of this ratio. Bernanke et al. (1999), in a costly verification model, show that the optimal financial contract between a risk-neutral intermediary and entrepreneur takes the form of a risk premium given by (43). Thus the risk premium is an increasing function of leverage of the firm. Following these authors, in the general equilibrium we ignore monitoring costs.

We now introduce entrepreneurs who own the capital of wholesale firms and who exit with a given probability $1-\xi_{e}$. Then the net worth accumulates according to

$$
N_{t+1}=\xi_{e} V_{t}+\left(1-\xi_{e}\right) D_{t}^{e}
$$

where $D_{t}^{e}$ are transfers from exiting to newly entering entrepreneurs continuing, and $V_{t}$, the net value carried over from the previous period, is given by

$$
V_{t}=\left(1+R_{k, t}\right) Q_{t-1} K_{t}-\Theta_{t}\left(1+R_{t}\right)\left(Q_{t-1} K_{t}-N_{t}\right)
$$

where $R_{k, t}$ is the ex post return given by

$$
1+R_{k, t}=\frac{\left(1-\alpha_{I}\right) \frac{P_{t}^{W}}{P_{t}} \frac{Y_{t}^{W}}{K_{t}}+(1-\delta) Q_{t}}{Q_{t-1}}
$$

Demand for capital is then given by

$$
E_{t}\left[1+R_{k, t+1}\right]=\frac{E_{t}\left[(1-\alpha) \frac{P_{t+1}^{W}}{P_{t+1}} \frac{Y_{t+1}^{W}}{K_{t+1}}+(1-\delta) Q_{t+1}\right]}{Q_{t}}
$$

Finally, exiting entrepreneurs consume the residual equity so that their consumption

$$
C_{t}^{e}=\frac{1-\xi_{e}}{\xi_{e}} N_{t}
$$

must be added to total consumption. The full model is summarized in Appendix A with the previous model as a special case. 


\subsection{BAYESian Estimation For India}

The model with financial frictions defines extra parameters which we now try to estimate for India. These are the proportion of liquidity constrained consumers $\lambda$, the elasticity of the external finance premium with respect to leverage $\chi$ in (43), the entrepreneurs survival rate $\xi^{e}$ and the leverage ratio $n_{k}$. Additionally, the model depends on the financial accelerator risk premium parameter $\Theta$, which we choose to calibrate at 1.01 (additional sensitivity analysis suggests that other reasonable values for $\Theta$ delivers similar results).

Thus, we maintain the priors used for the baseline model and define additional priors for newly estimated parameters. In the case of $\chi$, we assume an inverse gamma with a mean of 0.05, following Bernanke et al. (1999). Given that the remaining parameters are expected to be between 0 and 1, we use beta distributions. For $\lambda$, we assume that $40 \%$ of households in India are unable to optimize their consumption, with standard error of 0.1. ${ }^{12}$ We follow Gertler et al. (2003) in setting the mean of $\xi_{e}$ equal to 0.93, with a standard deviation of 0.05 . For the leverage ratio parameter $n_{k}$, required to set $k$ in (43), we choose the midpoint of the unit interval, with a standard deviation of 0.1 .

The sixth column of Table 3 contains the posterior estimates of the model discussed above. First, the improvement in model fit is significant. The log marginal density is now -356.3 , which corresponds to a Bayes factor of nearly 15 , with a posterior model probability of $94 \%$. This means that the data indicates that adding the financial frictions discussed in this section is indispensable.

The added parameters are all statistically significant, estimated with reasonable precision and within the expected bounds, apart from $\lambda$. Indeed, the proportion of liquidity constrained households is found to be around $20 \%$, somewhat below our prior.

Nevertheless, the quality of this model can also be gauged by analyzing the parameters estimated previously. In general, estimates are more precise and sensible. $\alpha$, for instance, is now retrieved with great accuracy, with its estimate nearly coinciding with the long run average in the data. Importantly, the parameters of the estimated Calvo-type interest rate feedback rule imply that the RBI assigns a larger weight to inflation, both expected and past, with values of 2.42 and 1.64 for $\theta$ and $\phi$, respectively. The corresponding forwardbackward looking horizons, given by $\varphi$ and $\tau$ remain similar to the previous model, though.

\footnotetext{
${ }^{12}$ There is an important connection between the size of non-Ricardian households $(\lambda)$ and model indeterminacy. For instance, Gali et al. (2004) find that the presence of non-Ricardian consumers may alter dramatically the properties of simple interest rules using an otherwise standard NK model. In particular, one of their main results is that the size of the inflation coefficient that is required in order to rule out multiple equilibria is an increasing function of the weight of rule-of-thumb consumers in the economy. Following Gali et al. (2004), we carry out a number of simulations using a standard NK model with rule-of-thumb consumers and a Taylor-type interest rate. Based on a set of conventional parameter values, our simulation results indeed confirm that the size of $\lambda$ is an increasing function of the inflation coefficient $\theta$. For a set of $\theta=[1.5,2,3,15]$, the threshold values of $\lambda$ must be around $0.30,0.31,0.32,0.40$, respectively, in order to guarantee the uniqueness of system equilibrium. When $\lambda$ takes a high value under such a rule, the size of $\theta$ required for the avoidance of indeterminacy may be too large to be credible. For this reason, we choose a truncated prior for $\lambda$ that has an upper bound of 0.4 in this and following sections. The detailed set of simulation results is available upon request.
} 
Another distinct feature is the persistence of the exogenous shocks, now estimated to be higher, though not for the mark-up shock. The associated standard errors are somewhat smaller, in particular the risk premium shock, perhaps reflecting the model's ability to capture additional uncertainty. Nevertheless, they are still high when compared to the ones found in the literature in the case of developed economies. Note, however, that the Calvo probability $\xi$ is still below the prior, again indicating a large frequency of price adjustments (every 1-2 quarters).

\section{A Two-Sector NK Model with an Informal Sector}

We now consider a two-sector "Formal" (F) and "Informal" (I) economy, producing different goods with different technologies which sell at different retail prices, $P_{F, t}$ and $P_{I, t}$, say. Monopolistic competition prevails in both I and $\mathrm{F}$ retail sectors. In the competitive wholesale sectors, labour and capital are the variable factor inputs and the informal sector is less capital intensive. The capital-producing sector is competitive as before. Both capital goods and government services are provided solely from the formal sector and the latter are financed by an employment tax. Thus, unlike the previous two models, taxes are now distortionary. In the general set-up, this can be shared by the formal and informal sectors, giving us a framework in which the role of tax incidence can be studied as one of the drivers of informality. The other drivers in our model are the degree of real wage rigidity in the formal sector and the credit constraints facing the informal sector.

Again, we allow a proportion of all households $1-\lambda$ to be Ricardian and $\lambda$ to be nonRicardian. Those who are Ricardian consume $C_{1, t}$. A proportion $n_{F, t}$ of their members work $h_{1 F, t}$ hours in the F-sector and a proportion $1-n_{F, t}$ work $h_{1 I, t}$ hours in the I-sector. Non-Ricardian (credit-constrained) households work $h_{2 I, t}$ hours only in the I-sector and consume $C_{2, t}$ out of current wage income.

\subsection{Dynamic Model}

Consider first the benchmark model without labour market or financial frictions. Ricardian households are described by the following utility function

$$
\Lambda_{1, t}=\Lambda\left(C_{1, t}, L_{1 F, t}, L_{1 I, t}\right)=\frac{C_{1, t}^{(1-\varrho)(1-\sigma)}\left(n_{F, t} L_{1 F, t}^{\varrho(1-\sigma)}+\left(1-n_{F, t}\right) L_{1 I, t}^{\varrho(1-\sigma)}\right)-1}{1-\sigma}
$$

which is a generalization of (1). As before we need their marginal utilities os consumption and leisure given respectively by

$$
\begin{aligned}
\Lambda_{C_{1}, t} & =(1-\varrho) C_{1, t}^{(1-\varrho)(1-\sigma)-1}\left(n_{F, t} L_{1 F, t}^{\varrho(1-\sigma)}+\left(1-n_{F, t}\right) L_{1 I, t}^{\varrho(1-\sigma)}\right) \\
\Lambda_{L_{1 i}, t} & =\varrho C_{1, t}^{(1-\varrho)(1-\sigma)}\left(L_{i, t}\right)^{\varrho(1-\sigma)-1} ; i=I, F
\end{aligned}
$$


Then consumption-savings and labour supply (hours worked) decisions are given by

$$
\begin{aligned}
\Lambda_{C_{1}, t} & =\beta E_{t}\left[\left(1+R_{t+1}\right) \Lambda_{C_{1}, t+1}\right] \\
\frac{\Lambda_{L_{1 i, t}}}{\Lambda_{C_{1}, t}} & =\frac{W_{i, t}}{P_{t}} ; i=I, F \\
h_{1 i, t} & \equiv 1-L_{1 i, t} ; i=I, F
\end{aligned}
$$

Equation (49) is the Euler consumption function for Ricardian households. Equation (50) equates the marginal rate of substitution between consumption and leisure with the real wage, the relative price of leisure, and (51) defines hours worked for members of the household working in each sector.

Non-Ricardian households consume out of current wage income and are described by counterparts to $(49)-(50)$ given by

$$
\begin{aligned}
C_{2, t} & =h_{2 I, t} \frac{W_{I, t}}{P_{t}} \\
\frac{\Lambda_{L_{2 I, t}}}{\Lambda_{C_{2}, t}} & =\frac{W_{I, t}}{P_{t}} \\
L_{2 I, t} & \equiv 1-h_{2 I, t}
\end{aligned}
$$

Then total per capita consumption is given by

$$
C_{t}=(1-\lambda) C_{1, t}+\lambda C_{2, t}
$$

and this completes the household sector of the model.

There are informal and formal wholesale and retail sectors. Let $N_{i, t}$ be the total labour supply to sector $i=I, F$. Then the wholesale sectors each produce a homogeneous good using the technology

$$
\begin{aligned}
Y_{i, t}^{W} & =F\left(A_{i, t}, n_{i, t}, h_{i, t}, K_{i, t}\right)=\left(A_{i, t} H_{i, t}\right)^{\alpha_{i}} K_{i, t}^{1-\alpha_{i}} \\
N_{F, t} & \equiv(1-\lambda) n_{F, t} h_{1 F, t} \\
N_{I, t} & \equiv(1-\lambda)\left(1-n_{F, t}\right) h_{1 I, t}+\lambda h_{2 I, t}
\end{aligned}
$$

Homogeneous wholesale output is converted into a differentiated good $m$ according to

$$
Y_{i, t}(m)=\left(1-c_{i}\right) Y_{i, t}(m)^{W}
$$

Wholesale firms employ labour up to the point where the marginal product of labour equals the cost of labour which now includes an employment tax $\tau_{i, t}, i=I, F$.

$$
\frac{P_{i, t}^{W}}{P_{t}} F_{N_{i}, t}=\frac{P_{i, t}^{W}}{P_{t}} \frac{\alpha_{i} Y_{i, t}^{W}}{N_{i, t}}=\frac{W_{i, t}}{P_{t}}\left(1+\tau_{i, t}\right)
$$


This allows for the possibility of some tax incidence in the informal sector, but in fact we proceed on the basis on the informal sector is untaxed, so $\tau_{I, t}=0$.

Introducing labour market frictions, we assume that the real wage in the formal sector given by a real wage norm $R W_{t}$ that is a mark-up $r w$ on the real wage in the informal sector:

$$
\frac{W_{F, t}}{P_{t}}=R W_{t}=(1+r w) \frac{W_{I, t}}{P_{t}} ; r w>0
$$

From $R W_{t}>\frac{W_{I, t}}{P_{t}}$, it follows from $U_{L L}<0$ that the household will choose less leisure and more work effort in the formal sector; i.e., $h_{F, t}>h_{I, F}$.

Capital is accumulated by capital-producing firms out of F-output as before. Again we model the risk premium by introducing financial accelerators in each sector with different parameters.

The remaining difference to be considered is the demand side of the model. We construct Dixit-Stiglitz consumption and price aggregates

$$
\begin{aligned}
& C_{t}=\left[\mathrm{w}^{\frac{1}{\mu}} C_{F, t}^{\frac{\mu-1}{\mu}}+(1-\mathrm{w})^{\frac{1}{\mu}} C_{I, t}^{\frac{\mu-1}{\mu}}\right]^{\frac{\mu}{\mu-1}} \\
& P_{t}=\left[\mathrm{w}\left(P_{F, t}\right)^{1-\mu}+(1-\mathrm{w})\left(P_{I, t}\right)^{1-\mu}\right]^{\frac{1}{1-\mu}}
\end{aligned}
$$

where $\mu$ is the elasticity of substitution between $\mathrm{I}$ and $\mathrm{F}$ goods, and $\mathrm{w}$ is the relative weight of consumers in their preferences. Then standard inter-temporal and intra-temporal optimizing decisions lead to

$$
\begin{aligned}
C_{F, t} & =\mathrm{w}\left(\frac{P_{F, t}}{P_{t}}\right)^{-\mu} C_{t} \\
C_{I, t} & =(1-\mathrm{w})\left(\frac{P_{I, t}}{P_{t}}\right)^{-\mu} C_{t}
\end{aligned}
$$

Let $\mathcal{T}_{t}=\frac{P_{I, t}}{P_{F, t}}$ be the relative price of the retail consumption basket in the two sectors. Then we have

$$
\begin{aligned}
\frac{P_{F, t}}{P_{t}} & =\frac{1}{\left[\mathrm{w}+(1-\mathrm{w}) \mathcal{T}_{t}^{1-\mu}\right]^{\frac{1}{1-\mu}}} \\
\frac{P_{I, t}}{P_{t}} & =\frac{1}{\left[\mathrm{w} \mathcal{T}_{t}^{\mu-1}+1-\mathrm{w}\right]^{\frac{1}{1-\mu}}} \\
\frac{\mathcal{T}_{t}}{\mathcal{T}_{t-1}} & =\frac{\Pi_{I, t}}{\Pi_{F, t}} \\
\frac{\Pi_{F, t}}{\Pi_{t}} & =\left[\frac{\mathrm{w}+(1-\mathrm{w}) \mathcal{T}_{t-1}^{1-\mu}}{\mathrm{w}+(1-\mathrm{w}) \mathcal{T}_{t}^{1-\mu}}\right]^{\frac{1}{1-\mu}}
\end{aligned}
$$

where $\Pi_{i, t}, i=I, F$ and $\Pi_{t}$ are sector and CPI inflation rates respectively. We assume that 
government services are provided by the formal sector. Then output equilibrium in both sectors is given by

$$
\begin{aligned}
Y_{F, t} & =C_{F, t}+G_{t}+I_{t} \\
Y_{I, t} & =C_{I, t}
\end{aligned}
$$

The pricing dynamics in the two sectors follows as before, as do the shock processes, but now we have mark-up, technology and risk premia shocks in both sectors. The model is closed with an inflation targeting rule for CPI inflation. The full model is summarized in Appendix B. Figure 1 illustrates the interconnections of this model structure.

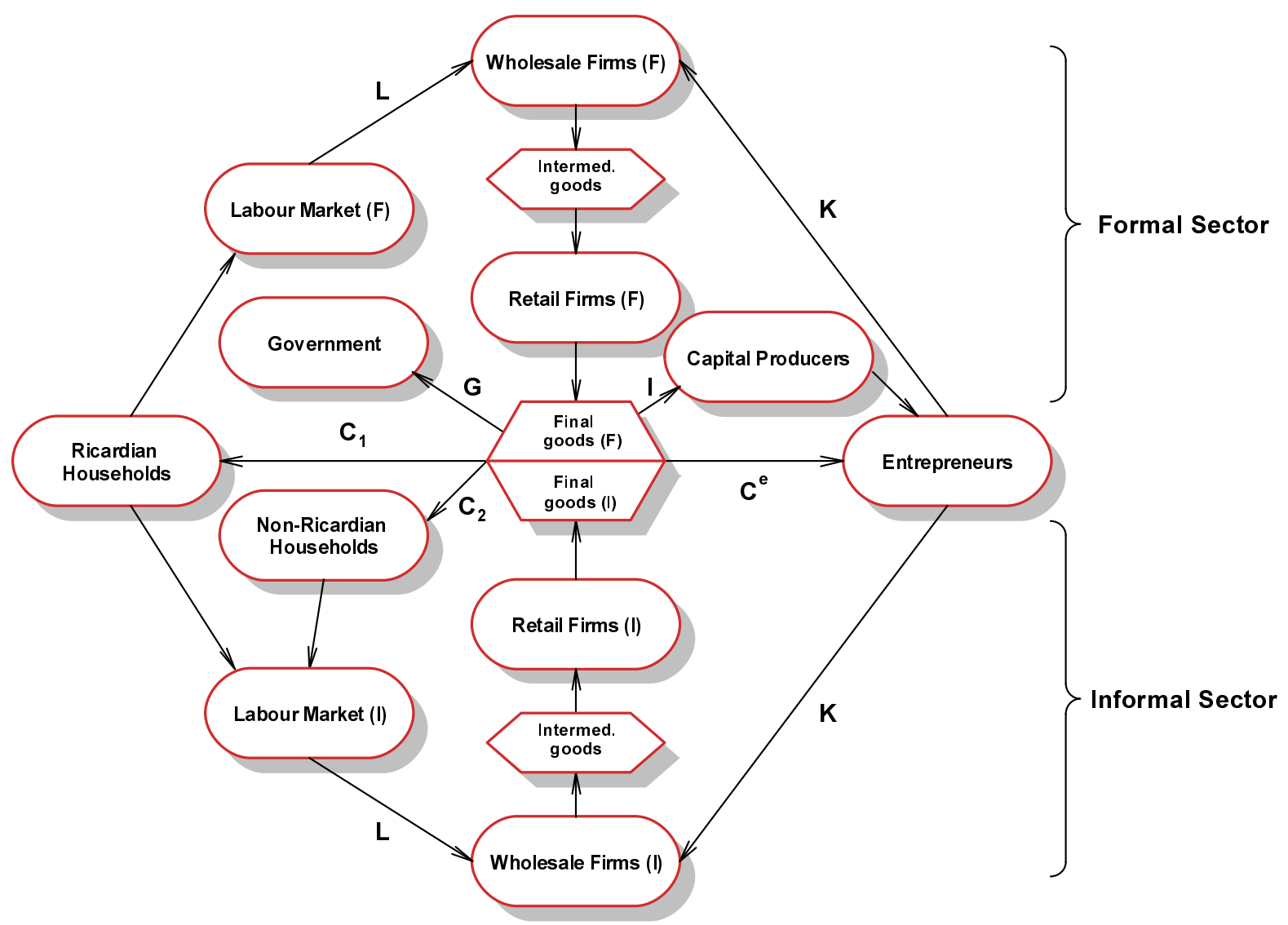

Figure 1: Two-Sector NK Model Structure

\subsection{Bayesian Estimation For India}

The model discussed above introduces further transmission mechanisms that may be important for the conduct of monetary policy. Thus, we now assess how well this extended model fits the data for India. Note that we now have several structural parameters defined for both the formal and informal sectors. In particular, we wish to ascertain the differences 
between the two sectors in terms of labour intensity $\left(\alpha_{F}\right.$ and $\left.\alpha_{I}\right)$, the degree of price stickiness $\left(\xi_{F}\right.$ and $\left.\xi_{I}\right)$, market power $\left(\zeta_{F}\right.$ and $\left.\zeta_{I}\right)$, the elasticity of substitution between goods in the formal and informal sectors $(\mu)$, the degree of real wage rigidity $\left(r_{W}\right)$, the size of the informal sector $\left(w, r e l_{Y}\right.$ and $\left.r e l_{n}\right)$, and financial frictions $\left(\chi_{F}\right.$ and $\chi_{I}, n_{k_{F}}$ and $n_{k_{I}}, \xi_{F}^{e}$ and $\left.\xi_{I}^{e}\right)$. We also allow for sector-specific technology and mark-up shocks, and we attempt to estimate the relative size of the informal sector.

In terms of priors for the new set of parameters, we maintain those used for the aggregate economy model estimated in the previous section. In terms of the size of the informal sector, given by $1-w$, for which we have no prior information, we estimate a dimensionless quantity: the relative nominal outputs for the two sectors $r e l_{Y}$ instead of estimating $w$. We normalize $A_{I}=A_{F}=1.0$ and choose prior means (that will hit $r e l_{n}=0.2$ approximately), of $r w=0.75$, rel $_{Y}=1.0, \alpha_{F}=0.6$ and $\alpha_{I}=0.8$. See Appendix B for more details on the calibration and prior settings of the parameters related to the size of informality. For the additional parameter $\mu$, we assume a normal prior centred around 1.5 with a standard deviation of 0.2 . On the other hand, we impose a beta distribution centred at 0.75 for the degree of wage rigidities $r_{W}$, with a standard deviation of 0.1 . Note that the model depends on other parameters, which we calibrate, namely a sector-specific financial accelerator risk premium $\left(\Theta_{F}\right.$ and $\left.\Theta_{I}\right)$, the latter fixed at 1.06, as one would expect a higher risk premium associated with the informal sector. ${ }^{13}$

The posterior estimates and confidence intervals for this model are presented in the rightmost column of Table 3 . The two bottom lines of Table 3 report the log marginal likelihood and posterior model probabilities comparing the three models under study. A striking result is the substantial improvement in fit achieved by the two-sector model over the simpler financial frictions model. Indeed, the difference in the log likelihoods is remarkable, lending unequivocal support to the third model compared with the second and very strong support for the second compared with the first. ${ }^{14}$

The model also produces other interesting results. In terms of the formal-informal dichotomy, the data is informative about the size of the informal sector as the relative nominal outputs for the two sectors is 1.15 and the relative numbers of workers employed in the formal sector are 0.28 , which gives us a rather lower estimate for the size relative to our prior assumptions, but still consistent with much of the evidence on informality in India. In addition, we learn that the shock processes are more persistent and more volatile in the informal sector, which seems a plausible outcome. Likewise, the estimated model indicates that the informal sector is more labour intensive, as $\alpha_{I}$ is larger than $\alpha_{F}$.

In terms of the financial friction mechanisms, differences are less marked. Although the

\footnotetext{
${ }^{13}$ See Haugen (2005) for some empirical support for this prior.

${ }^{14}$ Using $p_{i}=p_{1} B F(i, 1)$ and (38) the model probabilities calculated from the estimated posterior distribution are $0.9959,0.0039$ and 0.0003 for the third, second and first model respectively. According to Jeffreys (1961) this constitutes "decisive evidence" in favour of the third over the second model, and "strong to very strong evidence" of the second over the first - see Dejong and Dave (2007), chapter 9 for a useful discussion of model comparison.
} 
model correctly points to a higher entrepreneurs survival rate and a lower leverage ratio in the formal sector, the parameter $\chi$ is somewhat larger in the formal sector, but not statistically different from the informal economy case.

One interesting aspect revealed by these estimates is that prices are estimated to be a lot stickier in the formal sector, with an estimated frequency of price adjustments around 4 quarters, while it remains low for the informal sector, consistent with the estimates obtained previously. This suggests that prices in the informal sector are more flexible. However, the model confirms that there is a sizeable degree of wage rigidities, with the estimated $r_{W}$ close to our prior. On the other hand, the estimated parameters capturing the policy response to inflation largely confirm that the RBI appears to be quite aggressive in preempting inflationary pressures, particularly expected future inflation. Indeed, $\theta$ is again higher than 2 , with a somewhat lower $\phi$. The policy horizons are again estimated to be on the short-term side, approximately 1 quarter.

Another distinct feature of these new estimates concerns the size of the standard error for the government spending shock. While most of the shocks appear to be of the same magnitude as before, this model suggests that a great deal more volatility is is being transmitted by the fiscal side of the economy. One possible explanation is that all sorts of exogenous uncertainty, and potential misspecifications (particularly on the demand side) are being picked up by this shock process. Note that we do not explicitly model fiscal policy and we have circumscribed our analysis to the closed economy case. All in all, this suggests that careful modelling of fiscal policy and the open economy might be required to understand this result better.

\section{Empirical Applications}

After having shown the model estimates and the assessment of relative model fit to its other rivals with different restrictions, we use them to investigate a number of key macroeconomic issues in India. The model favoured in the space of competing models may still be poor (potentially misspecified) in capturing the important dynamics in the data. To further evaluate the absolute performance of one particular model against data, it is necessary to compare the model's implied characteristics with those of the actual data. Also in this section, we address the following questions: (i) can the models capture the underlying characteristics of the actual data? (ii) what are the driving forces of the observed business cycle fluctuations? (iii) what are the impacts of the structural shocks on the main macroeconomic time series?

\subsection{Further Model Validation}

Summary statistics such as first and second moments have been standard as means of validating models in the literature on DSGE models, especially in the RBC tradition. As the Bayes factors (or posterior model odds) are used to assess the relative fit amongst a number of competing models, the question of comparing the moments is whether the models 
correctly predict population moments, such as the variables' volatility or their correlation, i.e. to assess the absolute fit of a model to macroeconomic data. In practice, one could compute a Taylor approximation around the computed steady state of order one or two (for a model that is not log-linearized). By computing approximated (Taylor) decision rules and transition equations (the equations listing current values of the endogenous variables of the model as a function of the previous state of the model and current shocks) for the model by a perturbation method. At this stage, one could simulate the model and compute the simulated moments by assuming that the shocks follow a normal distribution. In what follows, all theoretical moments, correlation and autocorrelation coefficients, impulse responses and variance decomposition are computed based on the solutions of estimated models of order one.

\subsection{Standard Moment Criteria}

To assess the contributions of assuming different specifications in our estimated models, we compute some selected second moments and present the results in this subsection. Tables 4 and 5 present the second moments implied by the above estimations and compares with those in the actual data. In particular, we compute these model-implied statistics by solving the models at the posterior means obtained from estimation. The results of the model's second moments are compared with the second moments in the actual data to evaluate the models' empirical performance.

First it is interesting to note that the data exhibit higher volatility in real GDP and real investment for the US than for India. There are two reasons for this: i) the sample size used for the US (1980:1-2006:4) is more than twice as large as that used for India (1996:1$2008: 4)$; ii) in the data transformation process in Section 2.5.2 we extract the cyclical components in GDP and investment using different filters for the US and Indian data. The differences in volatility are due to the filter used as each different filter extracts cycles with properties statistically different from each other. The magnitude of the standard deviations in the transformed data is affected by the choice of de-trending filters. The relatively larger standard deviation in the US data occurs because a linear de-trending filter does not remove entirely the low frequencies from the spectral density representation, and leaves in the spectrum a large portion of persistent fluctuations (see Ferroni (2010) and Section 6 for more discussions on data-filtering).

For the moment analysis in this subsection, we focus on the Indian economy. In terms of the standard deviations, almost all models generate relative high volatility compared to the actual data (except for the interest rate). By providing a feedback from the shocks to net worth, the financial accelerator increases the volatilities of output and investment. Inflation volatility is practically unchanged owing to the higher responsiveness (and volatility) of the interest rate. Overall, the estimated models are able to reproduce acceptable volatility for the main variables of the DSGE model. The inflation volatilities implied by the models are close to that of the data. In line with the Bayesian model comparison, the NK models with 
financial frictions fit the data better in terms of implied volatilities of inflation and interest rate, getting closer to the data in this dimension. Note that our 'best' 2-sector model clearly outperforms the other two models in capturing the volatilities of output, inflation and interest rate and does extremely well at matching the inflation volatility in the data.

Table 5 also reports the cross-correlations of the four observable variables vis-a-vis output. All models perform successfully in generating the positive contemporaneous correlations observed in the data. It is worth noting that our 'preferred' model, 2-sector NK model, does very well at capturing the contemporaneous cross-correlation of the interest rate and output, suggesting that the financial accelerator and informal sector help fitting the Indian data in this dimension. The 2-sector NK model appears to match well the autocorrelations (order $=1$ ) of interest rate and investment. Using this model, output is more autocorrelated while inflation seems to be less autocorrelated then those in the data at order 1. Nevertheless, the 2 -sector NK model, in general, is able to capture the main features of the data in most dimensions and strengthens the argument that the presence of financial friction mechanisms and informality is supported by the data.

\subsection{Unconditional Autocorrelations}

To further illustrate how the estimated models capture the data statistics, we plot the unconditional autocorrelations of the actual data and those of the endogenous variables generated by the model variants in Figure 9. In general, all models match reasonably well the autocorrelations of output, interest rate and investment shown in the data within a shorter period horizon. The data report that these three variables are positively and very significantly autocorrelated over short horizons. At lags of one-two quarters, all the estimated models are able to generate the observed autocorrelations of interest rate and investment as noted above. Output is more autocorrelated in all models than in the data, but the 2-sector model with informality gets closer to the data towards the end of sample period. When it comes to matching inflation, all models exhibit the shortcoming of the inability of predicting the dynamics in the data.

Of particular interest is that, when assuming informality and/or the presence of financial frictions, the implied autocorrelograms produced by the 2-sector model and NK model with FA fit well the observed autocorrelation of interest rate, while the simplest NK model generates less sluggishness and is less able to match the autocorrelation observed in the data from the second lag onwards. The 2-sector model outperforms in terms of getting closer to the autocorrelation observed in the Indian GDP and investment. Overall, the results in this exercise generally show again that the estimated DSGE models are able to capture the some important features of Indian data and the presence of financial frictions and informality helps improve the model fit to data. 


\subsection{Variance Decomposition of Business Cycle Fluctuations}

This section investigates the contribution of each of the structural shocks to the forecast error variance of the observable variables in the models, i.e. the underlying sources of fluctuations, at various horizons. The results are based on the models' posterior distribution reported in Table 3. The focus of this exercise is on our 'preferred' 2-sector NK model and the results are summarized in Table 8.

In the short run, within a year $(\mathrm{t}=1,4)$, movements in real GDP are primarily driven by supply-side shocks (with the dominant influence of around 60\%). For instance, most of the unexpected output fluctuations are mainly explained by the technology shock in the informal sector (around 50\%) and the price mark-up shock in the informal sector (around 3-7\%). For the shocks that are associated to demand innovations, the government spending shock together with the risk premium shock account for about $30-40 \%$ of the output forecast error variance at the one-year horizon.

Not surprisingly, in the medium run the supply shocks and the risk premium shock together continue to dominate, and the government spending shock also explains around $22 \%$ of India's output variability. In the long run, the technology shock affecting the informal sector, the exogenous spending shock and the risk premium shock dominate, but the contribution of technology shock affecting the informal sector to output variability seems to become smaller from medium to long run and the risk premium shock seems to explain a bigger part of the long-run variations in output. In contrast, the monetary policy shock and mark-up shock in the formal sector do not seem to matter for output variability, regardless of forecast horizon.

Under the estimated interest rate, we find that the main determinant of the nominal interest rate in India is the risk premium shock, which explains around $46 \%$ to $76 \%$ of its forecast error variance from the short run to the long run. The second largest component is the government spending shock within a year $(25 \%)$ and the productivity shock in the informal sector and in the short run (around 20\%). This finding highlights the important role of productivity factors over the informal sector in the Indian economy. Interestingly, the shock that explains most of CPI inflation variance is the monetary policy shock. We find that it is by far the most dominant influence to the inflation variability (over 70\%) at all forecast horizons. In contrast, our estimated 2-sector NK model shows that inflation fluctuations are almost unaffected by either the productivity shock affecting the formal sector or price mark-up shocks and there are only limited effects on inflation from the informal productivity shock and various demand shocks. One reason for this is, according to Smets and Wouters (2007), that the estimated slope of the NK Phillips curve is very small (in particular in the formal sector), so that only large and persistent changes in the marginal cost will have an impact on inflation. Finally, the risk premium and government spending shocks together explain the largest part of investment in both the short run and the long run. 
It can also be seen in Tables 6 and 7 that the contributions of the selected shocks to the forecast error variance of the endogenous variables are broadly similar across the three models (especially between the models characterizing financial frictions). Perhaps one noteworthy discrepancy is exhibited by the contributions of the price mark-up shock to the variations in output implied by the NK model with financial frictions. The estimated model suggests that this shock has a noticeable effect on output, dominating the productivity shock.

Overall, the results show that the supply-side shocks account for some of the long-run variance which is in line with the business cycle literature and identified VAR studies in both industrialized and developing economies. The disturbances from government expenditures and the risk premium shock are very important at explaining the dynamics of macrovariables in the Indian economy. Finally the technological disturbances and price mark-up shock from the informal sector in India are more noticeable than these shocks affecting the formal sector. The findings in this analysis are consistent with our estimation results of 2-sector model reported in Table 3. In particular, the properties of all our estimation results clearly indicate a significant presence of informality in the observed data. In this section we show that the disturbances in the informal sector have a much greater impact on the dynamics of the economy, further highlighting the important role of informal sector over

the Indian economy. Moreover, Table 8 shows that the exogenous government spending shock contributes noticeable fractions of forecast variances of output, interest rate and investment and the estimated model suggests that a great deal more volatility is being transmitted persistently by the fiscal side of the Indian economy.

\subsection{Posterior Impulse Response Analysis}

We now compare the impulse response functions (IRFs) implied by the estimated models, in order to investigate the importance of each of the shocks to the dynamics of the endogenous variables. Figures 4 to 8 plot the deterministic mean responses corresponding to a positive one standard deviation of each shock's innovation. The IRFs show the quarterly percentage changes to the relevant variables about the their steady-state values. In the 2 -sector model, we confine the analysis to shocks to productivity, the price mark-up and the risk premium in the formal sector and output, investment, hours worked, marginal costs refer to that sector. Inflation refers to CPI inflation. Given our specification of real wage determination in the formal sector, percentage changes to the real wage are the same in the two sectors.

Before we compare the IRFs in the simple NK model I, the one-sector model II and two-sector model III both with financial frictions, the differences between the estimated Taylor rules should be noted. There is a similar degree of interest rate smoothing and degrees of forward-looking and backward-looking behaviour across all models, but the rules are far more aggressive in their response to CPI inflation in models II and III. This means that in comparing the IRFs, we are not making a simple comparison between models with or without financial frictions and informality. 
A positive productivity shock in the formal-sector leads to the usual positive impact on output, consumption, Tobin's Q (the price of capital) and investment. CPI inflation falls and, with our inflation-targeting Taylor rule in place, the nominal interest rate falls. This looser monetary policy stance after a lag leads to a prolonged period with the real interest rate below its steady state, so demand for consumption rises in line with supply. There are marked differences between model I on the one hand and models II and III with financial frictions. The latter, we recall, consist of the introduction of some credit constrained households and a financial accelerator.

Consider the labour market and the behaviour of the real wage. With sticky prices, the increase in demand for output is less than the 1 percent technology increase, so the demand for labour falls shifting the demand curve in (real-wage, quantity) space inwards. This puts an initial downward pressure on the real wage. On the supply-side of the labour market, since the marginal utility of consumption for the household falls as consumption rises, there is an increase in leisure (a reduction in hours) shifting the supply of labour curve outward, thus tending to raise the real wage. With liquidity constrained households consuming out of their wage income in models II and III, this boosts consumption and output further and shifts the demand curve back outwards. This liquidity effect dominates and we see hours worked stay almost at their steady state and the real wage rising in the two models with this feature. The marginal cost (the real price of wholesale output) moves with the factor costs: both costs of capital and labour fall in model I, but these more or less cancel out in models II and III leaving the marginal cost almost unchanged. With informality in model III, the positive productivity shock in the formal-sector leads to a fall in the relative price of output in that sector (a rise in $\frac{P_{I, t}}{P_{F, t}}$ in the figure). Changes in the terms of trade between the two sectors acts as a stabilizing cushion for investment, consumption, the real wage and Tobin's Q in rather the same way as the real exchange rate in a multi-country context. This we shall see is a feature in several of the IRFs reported.

Turning to the responses to a government spending shock, the striking feature is the presence of a 'classical' crowding-out effect. Indeed, the initial fiscal stimulus increases inflation, leading to an aggressive rise in the interest rate, which provokes a fall in private consumption and investment. This effect if significantly amplified in the presence of financial frictions and informality. On the other hand, a shock to the policy rule implies a significant reduction in the inflation rate, having positive real effects in terms of private investment and output.

There are now marked differences between models I and II on the one hand and models III with informality. Consider the labour market and the behaviour of the real wage. The increase in demand for output leads to a corresponding increase in supply and demand for labour - the demand for labour curve shifts outwards, putting an upward pressure on the real wage. The crowding-out of consumption results in a fall in consumption and a rise in its marginal utility; households reduce their leisure and increase hours shifting the supply curve inwards and putting downward pressure on the real wage. The liquidity effect means 
this reduces the consumption further and shifts the demand for labour back somewhat. The latter two effects cancel out the direct demand effect for model II and dominates for model III. This is driven by the quite small differences in the policy rules for models II and III which result in a tighter stance for model III, a higher real interest rate change and a sharp fall in consumption of Ricardian consumers. Hours worked and the real wage fall in the formal sector. There is now an important terms of trade effect. The concentration of the demand shock in the formal sector causes the relative rise of its output to rise, shifting demand to the informal sector. This squeezes investment (which comes entirely from the formal sector) further and it falls significantly more than in one-sector models I and II.

The monetary shock IRFs can largely be explained in terms of the different estimated rules. The positive shock to the nominal interest rate drives down inflation. In the more aggressive Taylor rules in models II and III this triggers a compensating strong downward adjustment to the interest rate, which now hardly moves from its steady state. The real interest rate in model I stays positive for several periods, diverging sharply from the other two models. Investment and Tobin's Q consequently fall. Consumption and investment demand are lower in model III and therefore output is as well. Since investment is formed entirely from the output of the formal sector, there is a shift in demand away from the formal sector and its terms of trade (the relative price $\frac{P_{I, t}}{P_{F, t}}$ in the figure) falls.

The price mark-up shock (in the formal sector for model III) perhaps produces the most interesting IRFs, in that they differ significantly across all three models. For all three models a positive price mark-up shock lowers demand for output (in the informal sector for the case of model III) and demand for labour shift inwards. The real wage falls and with it the marginal cost, offsetting the original shock. Monetary policy is contractionary in model I: both the nominal and real interest rate rises in response to the rise in the inflation rate, pushing the consumption of Ricardian households down, reducing investment and causing Tobin's Q to fall. In model II the fall in the real wage results in a drop in the consumption on non-Ricardian households, reducing demand for labour further and adding to the output fall. The marginal cost fall further offsetting the original inflation shock, so now inflation falls resulting now in a expansionary monetary response; both the nominal and real interest rate rises, now raising investment and causing Tobin's Q to rise. In model III the informal sector acts as a buffer, absorbing workers who are no longer employed in the formal sector and this dampens the output, consumption and hours worked effects seen in models I and II. The CPI inflation rate now includes informal sector inflation, which is directly affected by the shock. The monetary stance therefore lies between those for models I and II as do the investment and Tobin's Q paths.

A common risk premium shock in both sectors directly increases the cost of capital and this is amplified by the financial accelerator. Investment, output and Tobin's Q all fall. The demand for labour curve shifts inwards and hours worked fall. In model I the monetary stance is on average over 10 periods slightly contractionary, so Ricardian households save less and consume more. The more aggressive rules for models II and III see a 
more contractionary monetary stance so investment and Tobin's Q fall by less. Aggregate consumption includes that of entrepreneurs in models II and III and their fall in net worth sees consumption fall sharply in these two models and this reduces output demand still further. The main differences in IRFs for the risk premium shock is then between model I without a financial accelerator and models II and III which have this feature.

\section{Discussion and Future Developments: Open Economy AND POLICY}

In this chapter, we put forward a methodology to help understanding of India's business cycle. Though well rooted in the empirical New Keynesian DSGE framework, we discuss a number of novel features that address issues that are emerging-economies (and India, for that matter) specific. Indeed, the introduction of, on one hand, financial frictions in the form of liquidity constrained consumers and a financial accelerator mechanism, and, on the other hand, the distinction between a formal and an informal sector are not only realistic, but also conducive to a better empirical performance.

Nevertheless, there are limitations to our study. First, we believe that in the case of emerging economies, the role of trends in the data requires special attention. Andrle (2008), for example, argues that assumptions on trending behaviour should be explicitly modelled, rather than side-stepped by means of an ad-hoc filtering procedure. Alternatively, one can take an agnostic view regarding de-trending in DSGE models by following the one-step approach recently suggested by Ferroni (2010), in which filtering parameters are jointly estimated with structural parameters, thus allowing for formal statistical comparisons among different de-trending procedures.

Second, by confining our analysis to a closed-economy model, we leave out important sources of fluctuations. As with any open economy, emerging market economies are affected by external shocks. In addition, they are also vulnerable to sudden and sharp reversals of capital inflows, the "sudden stops" highlighted in Calvo (1998). Understanding these differences and carefully modeling the transmission mechanism of internal and external shocks is crucial to the understanding of real business cycle fluctuations and the design of stabilization policy.

In a series of papers, Batini et al. (2007), Batini et al. (2009) and Batini et al. (2010a), the authors develop a two-bloc model of an emerging open economy interacting with the rest of the world. The Indian economy is small in relation to the world economy and is therefore treated as a small open economy. Alongside standard features of small open economies (SOE) such as a combination of producer and local currency pricing for exporters and oil imports, their model incorporates financial frictions in the form of a financial accelerator, where capital financing is partly or totally in foreign currency, as in Gertler et al. (2003) and Gilchrist (2003). This intensifies the exposure of a SOE to internal and external shocks in a manner consistent with the stylized facts listed above. In addition, they allow 
for liability dollarization and liquidity-constrained households, which further amplify the effects of financial stress. In Batini et al. (2010a) they then focus on monetary policy analysis, calibrating (but not estimating as in this paper) the model using data for India and the US economy.

Many emerging economies conduct their monetary and fiscal policy according to the 'three pillars macroeconomic policy framework': a combination of a freely floating exchange rate, an explicit target for inflation over the medium run, and a mechanism that ensures a stable government debt-GDP ratio around a specified long run, but may allow for countercyclical adjustments of the fiscal deficit over the business cycle. By contrast, the currency monetary policy stance of the Indian Reserve Bank intervenes in the foreign exchange market to prevent what it regards as excessive volatility of the exchange rate. On the fiscal side, Central Government has a rigid fiscal deficit target of 3\% of GDP irrespective of whether the economy is in boom or recession, see Shah (2008). The framework adopted in the papers cited allow one to contrast these implied policy prescriptions for interest rate rules.

There is now a growing literature that compares alternative monetary policy regimes in their ability to stabilize emerging economies when faced with shocks and financial frictions. Some papers close to ours include Gertler et al. (2003), Cespedes et al. (2004), Cook (2004), Devereux et al. (2006) and Curdia (2008). All these papers confirm the result in Batini et al. (2010a) and in their other cited papers that flexible exchange rate regimes outperform a peg. Only Curdia (2008) compares these regimes with the optimal policy, but circumscribed to a deterministic exercise in which optimal policy is designed following a sudden stop. By contrast the rules examined in the Batini et al papers are optimal or, the case of simple rules optimized within the category or rule in anticipation of a range of future stochastic shocks. An important feature of their work is the introduction of a zero lower bound into the construction of policy rules.

Finally, future modelling developments will combine these open economy features with the introduction of a large informal sector as in this paper. We will then estimate the model by Bayesian-Maximum-Likelihood methods. ${ }^{15}$ In doing so we will confront the data limitations associated especially with the informal and partly hidden economy by adopting a consistent partial information assumption for the econometrician and private sector alike, as in Justiniano et al. (2008).

\section{REFERENCES}

Adolfson, M., Laseen, S., Linde, J., and Villani, M. (2008). Evaluating an estimated new Keynesian small open economy model. Journal of Economic Dynamics and Control,

\footnotetext{
${ }^{15}$ Anand et al. (2010) estimate and open economy model with many of the features in Batini et al. (2010a), but with no informal economy. Their results suggest support for the existence of a financial accelerator and liability dollarization.
} 
32(8), 2690-2721.

Agenor, P., McDermott, C. J., and Prasad, E. S. (2000). Macroeconomic Fluctuations in Developing Countries: Some Stylized Facts. The World Bank Economic Review, 14(2), 251-285.

Aguiar, M. and Gopinath, G. (2007). Emerging Market Business Cycles: The Cycle is the Trend. Journal of Political Economy, 115, 69-102.

Anand, R., Peiris, S., and Saxegaard, M. (2010). An Estimated Model with Macrofinancial Linkages for India. IMF Working Paper, WP/10/21.

Andrle, M. (2008). The Role of Trends and Detrending in DGSE Models. manuscript.

Barro, R. and Sala-i-Martin, X. (2004). Economic Growth. Second Edition, McGraw-Hill.

Batini, N., Levine, P., and Pearlman, J. (2007). Monetary Rules in Emerging Economies with Financial Market Imperfections. Presented to the NBER Conference on International Dimensions of Monetary Policy, S'Agaro, Catalonia, Spain, June 11-13, 2007 and NBER Conference Volume, International Dimensions of Monetary Policy, ed. J. Gali and M. Gertler.

Batini, N., Levine, P., and Pearlman, J. (2009). Monetary and Fiscal Rules in an Emerging Small Open Economy. IMF Working Paper, WP/09/22.

Batini, N., Gabriel, V., Levine, P., and Pearlman, J. (2010a). A Floating versus Managed Exchange Rate Regime in a DSGE Model of India . University of Surrey Working Paper.

Batini, N., Kim, Y.-B., Levine, P., and Lotti, E. (2010b). Informal Labour and Credit Markets: A Survey. IMF Working Paper, WP/10/42.

Bernanke, B., Gertler, M., and Gilchrist, S. (1999). The Financial Accelerator in Quantitative Business Cycles. In M. Woodford and J. B. Taylor, editors, Handbook of Macroeconomics, vol. 1C. Amsterdam: Elsevier Science.

Bhattacharya, R., Patnaik, I., and Shah, A. (2010). Monetary policy with a weak transmission mechanism. Working Paper, National Institute for Public Finance and Policy.

Brooks, P. and Gelman, A. (1998). General methods for monitoring convergence of iterative simulations. Journal of Computational and Graphical Statistics, , 7(4), 434-455.

Calvo, G. A. (1998). Capital Flows and Capital-Markets Crises. Journal of Applied Econometrics, 1(1), 35-54.

Carlstrom, C. T. and Fuerst, T. S. (1997). Agency costs, net worth and business cycle fluctuations: a computable general equilibrium analysis. American Economic Review, 87, 893-910. 
Cespedes, L. F., Chang, R., and Velasco, A. (2004). Balance Sheets and Exchange Rate Policy. American Economic Review, 94(4), 1183-1193.

Christiano, L. L. and Eichenbaum, M. (1992). Current real-business-cycle theories and aggregate labor-market fluctuations. American Economic Review, 82(2), 430-450.

Christiano, L. L., Eichenbaum, M., and Evans, C. L. (2005). Nominal rigidities and the dynamic effects of a shock to monetary policy. Journal of Political Economy, 113(1), $1-45$.

Cook, D. (2004). Monetary Policy in Emerging Markets. Journal of Monetary Economics, $\mathbf{5 1}(6), 1155-1181$.

Curdia, V. (2008). Optimal Monetary Policy under Sudden Stops. Federal Reserve Bank of New York, Staff Report no. 323.

Dejong, D. and Dave, C. (2007). Structural Macroeconometrics. Princeton University Press.

Devereux, M. B., Lane, P. R., and Xu, J. (2006). Exchange Rates and Monetary Policy in Emerging Market Economies. The Economic Journal, 116(511), 478-506.

Fernandez-Villaverde, J. (2009). The Econometrics of DSGE Models. CEPR Discussion Paper No. 7159 .

Fernandez-Villaverde, J. and Rubio-Ramirez, J. F. (2004). Comparing dynamic equilibrium models to data: a Bayesian approach. Journal of Econometrics, 123, 153-187.

Ferroni, F. (2010). Trend agnostic one step estimation of DSGE models. manuscript.

Gabriel, V. J., Levine, P., and Spencer, C. (2009). How Forward-Looking is the Fed? Direct Estimates from a 'Calvo-type' rule. Economics Letters, 104(2), 92-95.

Gali, J., Lopez-Salido, J., and Valles, J. (2004). Rule-of-Thumb Consumers and the Design of Interest Rate Rules. NBER Working Papers 10392, National Bureau of Economic Research.

Gertler, M., Gilchrist, S., and Natalucci, F. M. (2003). External Constraints on Monetary Policy and the Financial Accelerator. NBER Working Paper No. 10128.

Geweke, J. (1999). Computational Experiments and Reality. University of Minnesota and Federal Reserve Bank of Minneapolis.

Gilchrist, S. (2003). Financial Markets and Financial Leverage in a Two-Country WordEconomy. Central Bank of Chile Working Paper No. 228.

Haugen, N. (2005). The Informal Credit Market: A Study of Default and Informal Lending in Nepal. Mimeo, University of Bergen. 
Jeffreys, H. (1961). Theory of Probability. Oxford: Clarendon Press.

Justiniano, A., Levine, P., Perendia, G., and Pearlman, J. (2008). The Estimation of DSGE Models under Partial Information. Presented at the 14th International Conference on Computing in Economics and Finance, Paris, June 26-28, 2008. .

Kydland, F. and Prescott, E. (1982). Time to Build and Aggregate Fluctuations. Econometrica, 50, 1345-1370.

Levin, A., Onatski, A., Williams, J. C., and Williams, N. (2006). Monetary Policy Under Uncertainty in Micro-Founded Macroeconomic Models. in M. Gerler and K. Rogoff (eds.), NBER Macroeconomics Annual, 2005, pp 229-387 .

Levine, P., McAdam, P., and Pearlman, J. (2007). Inflation forecast rules and indeterminacy: a puzzle and a resolution. International Journal of Central Banking, 3, 77-110.

Litterman, R. B. (1983). A random walk, markov model for the distribution of time series. Journal of Business and Economics Statistics, 1(2), 169-173.

Marjit, S. and Kar, S. (2008). A Contemporary Perspective on the Informal Labor Market - Theory, Policy and the Indian Experience. Mimeo, Centre for Studies in Social Science, Calcutta.

Neumeyer, P. A. and Perri, F. (2005). Business cycles in emerging economies: the role of interest rates. Journal of Monetary Economics, 52, 345-380.

Rada, C. (2009). Formal and Informal Sectors in China and India: An Accounting-Based Approach . Mimeo, Working Paper No: 2009-02 University of Utah. .

Schorfheide, F. (2000). Loss function-based evaluation of DSGE models. Journal of Applied Econometrics, 15(6), 645-670.

Sen, P. and Kolli, R. (2009). Delhi Group on Informal Sector Contribution and Present Status . Mimeo, Ministry of Statistics and Programme Implementation, India. Paper Prepared for the Special IARIW-SAIM Conference on Measuring the Informal Economy in Developing Countries Kathmandu, Nepal, September 23-26.

Shah, A. (2008). New Issues in Macroeconomic Policy . NIPFP Working Paper No. 51.

Smets, F. and Wouters, R. (2003). An estimated Stochastic Dynamic General Equilibrium Model of the Euro Area. Journal of the European Economic Association, 1(5), 11231175 .

Smets, F. and Wouters, R. (2007). Shocks and Frictions in US business cycles: A Bayesian DSGE approach. American Economic Review, 97(3), 586-606. 
Virmani, V. (2004). Operationalising Taylor-type Rules for the Indian Economy: Issues and Some Results. Indian Institute of Management Ahmedabad Working Paper 2004-07-04.

\section{A Summary of One-Sector Model}

\section{A.1 Dynamic Model}

The following summarizes the dynamic model for both one-sector models of sections 2 and 3. Note that the baseline model in section 2 puts $\lambda=0$ and shuts down the financial accelerator.

$$
\begin{aligned}
& \Lambda_{t}=\Lambda\left(C_{2, t}, L_{t}\right)=\frac{\left(C_{2, t}^{(1-\varrho)} L_{t}^{\varrho}\right)^{1-\sigma}-1}{1-\sigma} \\
& \left.\Lambda_{C_{2}, t}=(1-\varrho) C_{2, t}^{(1-\varrho)(1-\sigma)-1}\left(1-h_{t}\right)^{\varrho(1-\sigma)}\right) \\
& \Lambda_{L, t}=\varrho C_{2, t}^{(1-\varrho)(1-\sigma)} L_{t}^{\varrho(1-\sigma)-1} \\
& \Lambda_{C_{2}, t}=\beta E_{t}\left[\left(1+R_{t+1}\right) \Lambda_{C_{2}, t+1}\right] \\
& \frac{\Lambda_{L, t}}{\Lambda_{C_{2}, t}}=\frac{W_{t}}{P_{t}} \\
& L_{t} \equiv 1-h_{t} \\
& C_{1, t}=\frac{W_{t} h_{t}}{P_{t}} \\
& C_{t}^{e}=\frac{1-\xi_{e}}{\xi_{e}} N_{t} \\
& C_{t}=\lambda C_{1, t}+(1-\lambda) C_{2, t}+C_{t}^{e} \\
& Y_{t}^{W}=F\left(A_{t}, h_{t}, K_{t}\right)=\left(A_{t} h_{t}\right)^{\alpha} K_{t}^{1-\alpha} \\
& Y_{t}=(1-c) Y_{t}^{W} \\
& \frac{P_{t}^{W}}{P_{t}} F_{h, t}=\frac{P_{t}^{W}}{P_{t}} \frac{\alpha Y_{t}^{W}}{h_{t}}=\frac{W_{t}}{P_{t}} \\
& P_{t}=\frac{1}{1-\frac{1}{\zeta}} P_{t}^{W} \\
& K_{t+1}=(1-\delta) K_{t}+\left(1-S\left(X_{t}\right)\right) I_{t} \\
& X_{t} \equiv \frac{I_{t}}{I_{t-1}} \\
& Q_{t}\left(1-S\left(X_{t}\right)-X_{t} S^{\prime}\left(X_{t}\right)\right)+E_{t}\left[\frac{1}{\left(1+R_{t+1}\right)} Q_{t+1} S^{\prime}\left(Z_{t+1}\right) \frac{I_{t+1}^{2}}{I_{t}^{2}}\right]=1 \\
& E_{t}\left[\left(1+R_{t+1}\right) \Theta_{t+1}\right]=E_{t}\left[1+R_{k, t+1}\right] \\
& 1+R_{k, t}=\frac{\left(1-\alpha_{I}\right) \frac{P_{t}^{W}}{P_{t}} \frac{Y_{t}^{W}}{K_{t}}+(1-\delta) Q_{t}}{Q_{t-1}} \\
& \Theta_{t}=s\left(\frac{N_{t}}{Q_{t-1} K_{t}}\right) R P_{t}=k\left(\frac{N_{t}}{Q_{t-1} K_{t}}\right)^{-\chi} R P S_{t}
\end{aligned}
$$




$$
\begin{aligned}
& N_{t+1}=\xi_{e} V_{t}+\left(1-\xi_{e}\right) D_{t}^{e} \\
& V_{t}=\left(1+R_{k, t}\right) Q_{t-1} K_{t}-\Theta_{t}\left(1+R_{t}\right)\left(Q_{t-1} K_{t}-N_{t}\right) \\
& S\left(X_{t}\right)=\phi_{X}\left(X_{t}-(1+g)\right)^{2} \\
& Y_{t}=C_{t}+G_{t}+I_{t} \\
& H_{t}-\xi \beta E_{t}\left[\Pi_{t+1}^{\zeta-1} H_{t+1}\right]=Y_{t} \Lambda_{C, t} \\
& J_{t}-\xi \beta E_{t}\left[\Pi_{t+1}^{\zeta} J_{t+1}\right]=\left(\frac{1}{1-\frac{1}{\zeta}}\right) Y_{t} \Lambda_{C, t} M S_{t} M C_{t} \\
& 1=\xi \Pi_{t}^{\zeta-1}+(1-\xi)\left(\frac{J_{t}}{H_{t}}\right)^{1-\zeta} \\
& M C_{t}=\frac{P_{t}^{W}}{P_{t}} \\
& 1+R_{t}=\frac{1+R_{n, t-1}}{\Pi_{t}} \\
& \log A_{t}-\log \bar{A}_{t}=\rho_{A}\left(\log A_{t-1}-\log \bar{A}_{t-1}\right)+\epsilon_{A, t} \\
& \log G_{t}-\log \bar{G}_{t}=\rho_{G}\left(\log G_{t-1}-\log \bar{G}_{t-1}\right)+\epsilon_{G, t} \\
& \log M S_{t}-\log M S=\rho_{M S}\left(\log M S_{t-1}-\log M S\right)+\epsilon_{M S, t} \\
& \log R P S_{t}-\log R P S=\rho_{R P S}\left(\log R P S_{t-1}-\log R P S\right)+\epsilon_{R P S, t} \\
& \log \left(\frac{1+R_{n, t}}{1+R_{n}}\right)=\rho \log \left(\frac{1+R_{n, t-1}}{1+R_{n}}\right)+\theta \log \frac{\Theta_{t}}{\Theta}+\phi \log \frac{\Phi_{t}}{\Phi}+\epsilon_{M P S, t} \\
& \log \Phi_{t}=\log \Pi_{t}+\tau \log \Phi_{t-1} \\
& \varphi E_{t}\left[\log \Theta_{t+1}\right]=\log \Theta_{t}-(1-\varphi) \log \left(\Pi_{t}\right)
\end{aligned}
$$

\section{A.2 Steady State}

The steady state now changes to

$$
\begin{aligned}
\bar{N}_{t} & =\frac{\left(1-\xi_{e}\right) \bar{D}_{t}}{\left(1-\xi_{e}\left(1+R_{k}\right)\right)} \\
1+R_{k} & =(1+R) s\left(\frac{\bar{N}_{t}}{\bar{K}_{t}}\right) \\
\bar{K}_{t} & =\frac{1-\alpha}{\bar{Y}_{k}+\delta}
\end{aligned}
$$

Choose a functional form:

$$
s\left(\frac{\bar{N}_{t}}{Q \bar{K}_{t}}\right)=k\left(\frac{\bar{N}_{t}}{Q \bar{K}_{t}}\right)^{-\chi}
$$

We obtain $\chi$ from econometric studies and we have data on the risk premium $\Theta=\frac{1+R_{k}}{1+R}$ and leverage (= borrowing/net worth)

$$
\ell=\frac{Q K-N}{N}=\frac{Q K}{N}-1=\frac{1}{n_{k}}-1
$$


defining $n_{k} \equiv \frac{N}{Q K}$. Then we can set the scaling parameter $k$ from (A.1) as

$$
k=\Theta n_{k}^{\chi}
$$

Then in the baseline steady state used to calibrate parameters, we put $\bar{N}_{t}=n_{k} \bar{K}_{t}$ and calibrate $\bar{D}$ from (A.1). Then the zero-inflation steady state and the calibrated $k$ are given by

$$
\begin{aligned}
1+R & =\frac{(1+g)^{1+(\sigma-1)(1-\varrho)}}{\beta} \\
Q & =\Pi=1 \\
\bar{Y}_{t} & =(1-c)\left(h_{t} \bar{A}_{t}\right)^{\alpha} \bar{K}_{t}^{1-\alpha} \\
\frac{\varrho \bar{C}_{2, t}}{(1-\varrho)(1-h)} & =\bar{W}_{t} \\
\bar{C}_{1, t} & =\bar{W}_{t} h \\
\frac{\alpha P^{W} \bar{Y}_{t}^{W}}{P h} & =\bar{W}_{t} \\
\frac{\bar{K}_{t}}{\bar{Y}_{t}^{W}} & =\frac{1-\alpha}{R_{k}+\delta} \\
1+R_{k} & =(1+R) \Theta \\
\Theta & =k n_{k}^{-\chi}=k\left(\frac{\bar{N}_{t}}{Q \bar{K}_{t}}\right)^{-\chi} \\
\bar{I}_{t} & =(\delta+g) \bar{K}_{t} \\
\bar{Y}_{t} & =\bar{C}_{t}+\bar{I}_{t}+\bar{G}_{t} \\
1 & =\frac{1}{1-\frac{1}{\zeta}} \frac{P^{W}}{P} \\
\bar{N}_{t} & =n_{k} \bar{K}_{t}=\frac{\left(1-\xi_{e}\right) \bar{D}_{t}}{\left(1-\xi_{e}\left(1+R_{k}\right)\right)}
\end{aligned}
$$

\section{B Summary of TwO-SECtor Model}

\section{B.1 Dynamic Model}

$$
\begin{aligned}
\Lambda_{1, t} & =\Lambda\left(C_{1, t}, L_{1 F, t}, L_{1 I, t}\right)=\frac{C_{1, t}^{(1-\varrho)(1-\sigma)}\left(n_{F, t} L_{1 F, t}^{\varrho(1-\sigma)}+\left(1-n_{F, t}\right) L_{1 I, t}^{\varrho(1-\sigma)}\right)-1}{1-\sigma} \\
\Lambda_{C_{1}, t} & =(1-\varrho) C_{1, t}^{(1-\varrho)(1-\sigma)-1}\left(n_{F, t} L_{1 F, t}^{\varrho(1-\sigma)}+\left(1-n_{F, t}\right) L_{1 I, t}^{\varrho(1-\sigma)}\right) \\
\Lambda_{L_{1 i}, t} & =\varrho C_{1, t}^{(1-\varrho)(1-\sigma)}\left(L_{i, t}\right)^{\varrho(1-\sigma)-1} ; i=I, F \\
\Lambda_{C_{1}, t} & =\beta E_{t}\left[\left(1+R_{t+1}\right) \Lambda_{C_{1}, t+1}\right]
\end{aligned}
$$




$$
\begin{aligned}
& \frac{\Lambda_{L_{1 i, t}}}{\Lambda_{C_{1}, t}}=\frac{W_{i, t}}{P_{t}} ; i=I, F \\
& L_{1 i, t} \equiv 1-h_{1 i, t} ; i=I, F \\
& C_{2, t}=h_{2 I, t} \frac{W_{I, t}}{P_{t}} \\
& \frac{\Lambda_{L_{2 I, t}}}{\Lambda_{C_{2}, t}}=\frac{W_{I, t}}{P_{t}} \\
& L_{2 I, t} \equiv 1-h_{2 I, t} \\
& C_{t}=(1-\lambda) C_{1, t}+\lambda C_{2, t} \\
& Y_{i, t}^{W}=F\left(A_{i, t}, n_{i, t}, h_{i, t}, K_{i, t}\right)=\left(A_{i, t} N_{i, t}\right)^{\alpha_{i}} K_{i, t}^{1-\alpha_{i}} \\
& N_{F, t} \equiv(1-\lambda) n_{F, t} h_{1 F, t} \\
& N_{I, t} \equiv(1-\lambda)\left(1-n_{F, t}\right) h_{1 I, t}+\lambda h_{2 I, t} \\
& Y_{i, t}=\left(1-c_{i}\right) Y_{i, t}^{W} \\
& \frac{P_{i, t}^{W}}{P_{t}} F_{N_{i}, t}=\frac{P_{i, t}^{W}}{P_{t}} \frac{\alpha_{i} Y_{i, t}^{W}}{N_{i, t}}=\frac{W_{i, t}}{P_{t}}\left(1+\tau_{i, t}\right) \\
& K_{t+1}=(1-\delta) K_{t}+\left(1-S\left(X_{t}\right)\right) I_{t} \\
& X_{t} \equiv \frac{I_{t}}{I_{t-1}} \\
& Q_{t}\left(1-S\left(X_{t}\right)-X_{t} S^{\prime}\left(X_{t}\right)\right)+E_{t}\left[\frac{1}{\left(1+R_{t+1}\right)} Q_{t+1} S^{\prime}\left(Z_{t+1}\right) \frac{I_{t+1}^{2}}{I_{t}^{2}}\right]=1 \\
& S\left(X_{t}\right)=\phi_{X}\left(X_{t}-(1+g)\right)^{2} \\
& E_{t}\left[\left(1+R_{i, t+1}\right) R P_{i, t+1}\right]=\frac{E_{t}\left[\left(1-\alpha_{i}\right) \frac{P_{i, t+1}^{W} Y_{i, t+1}^{W}}{P_{t+1} K_{i, t+1}}+(1-\delta) Q_{t+1}\right]}{Q_{t}} \equiv E_{t}\left[\frac{Z_{i, t+1}}{Q_{t}}\right] \\
& \operatorname{PREM}_{i, t}=R_{I, t}-R_{t} \\
& Y_{F, t}=C_{F, t}+G_{t}+I_{t} \\
& Y_{I, t}=C_{I, t} \\
& C_{F, t}=\mathrm{w}\left(\frac{P_{F, t}}{P_{t}}\right)^{-\mu} C_{t} \\
& C_{I, t}=(1-\mathrm{w})\left(\frac{P_{I, t}}{P_{t}}\right)^{-\mu} C_{t} \\
& \frac{P_{F, t}}{P_{t}}=\frac{1}{\left[\mathrm{w}+(1-\mathrm{w}) \mathcal{T}_{t}^{1-\mu}\right]^{\frac{1}{1-\mu}}} \\
& \frac{P_{I, t}}{P_{t}}=\frac{1}{\left[\mathrm{w} \mathcal{T}_{t}^{\mu-1}+1-\mathrm{w}\right]^{\frac{1}{1-\mu}}} \\
& \frac{\mathcal{T}_{t}}{\mathcal{T}_{t-1}}=\frac{\Pi_{I, t}}{\Pi_{F, t}} \\
& \frac{\Pi_{F, t}}{\Pi_{t}}=\left[\frac{\mathrm{w}+(1-\mathrm{w}) \mathcal{T}_{t-1}^{1-\mu}}{\mathrm{w}+(1-\mathrm{w}) \mathcal{T}_{t}^{1-\mu}}\right]^{\frac{1}{1-\mu}}
\end{aligned}
$$




$$
\begin{aligned}
& H_{i, t}-\xi_{i} \beta E_{t}\left[\Pi_{i, t+1}^{\zeta_{i}-1} H_{i, t+1}\right]=Y_{i, t} \Lambda_{C, t} \\
& J_{i, t}-\xi_{i} \beta E_{t}\left[\Pi_{i, t+1}^{\zeta_{i}} J_{i, t+1}\right]=\left(\frac{1}{1-\frac{1}{\zeta_{i}}}\right) Y_{i, t} \Lambda_{C_{1}, t} M S_{i, t} M C_{i, t} \\
& 1=\xi_{i} \Pi_{i, t}^{\zeta_{i}-1}+\left(1-\xi_{i}\right)\left(\frac{J_{i, t}}{H_{i, t}}\right)^{1-\zeta_{i}} \\
& M C_{i, t}=\frac{P_{i, t}^{W}}{P_{i, t}} \\
& \frac{P_{F, t}}{P_{t}} G_{t}=n_{F, t} h_{F, t} \tau_{F, t} \frac{W_{F, t}}{P_{t}}+n_{I, t} h_{I, t} \tau_{I, t} \frac{W_{I, t}}{P_{t}} \\
& \tau_{I, t}=k \tau_{F, t} \\
& 1+R_{t}=\frac{1+R_{n, t-1}}{\Pi_{t}} \\
& \log A_{i, t}-\log \bar{A}_{i, t}=\rho_{A_{i}}\left(\log A_{i, t-1}-\log \bar{A}_{i, t-1}\right)+\epsilon_{A_{i}, t} \\
& \log G_{t}-\log \bar{G}_{t}=\rho_{G}\left(\log G_{t-1}-\log \bar{G}_{t-1}\right)+\epsilon_{G, t} \\
& \log M S_{i, t}-\log M S_{i}=\rho_{M S_{i}}\left(\log M S_{i, t-1}-\log M S_{i}\right)+\epsilon_{M S_{i}, t} \\
& \log R P S_{i, t}-\log R P S_{i}=\rho_{R P S_{i}}\left(\log R P S_{i, t-1}-\log R P S_{i}\right)+\epsilon_{R P S_{i}, t} \\
& \log \left(\frac{1+R_{n, t}}{1+R_{n}}\right)=\rho \log \left(\frac{1+R_{n, t-1}}{1+R_{n}}\right)+\theta \log \frac{\Theta_{t}}{\Theta}+\phi \log \frac{\Phi_{t}}{\Phi}+\epsilon_{M P S, t} \\
& \log \Phi_{t}=\log \Pi_{t}+\tau \log \Phi_{t-1} \\
& \varphi E_{t}\left[\log \Theta_{t+1}\right]=\log \Theta_{t}-(1-\varphi) \log \left(\Pi_{t}\right) \\
& \frac{W_{F, t}}{P_{t}}=R W_{t}=(1+r w) \frac{W_{I, t}}{P_{t}} \\
& 1+R_{i, t} \equiv \Theta_{i, t}\left(1+R_{t}\right) \\
& \Theta_{i, t}=s_{i}\left(\frac{N_{i, t}}{Q_{t-1} K_{i, t}}\right) ; s^{\prime}(\cdot)<0 \\
& N_{i, t+1}=\phi_{i} V_{i, t}+\left(1-\phi_{i}\right) D_{i, t} \\
& V_{i, t}=\left(1+R_{i, t}^{k}\right) Q_{t-1} K_{i, t}-\Theta_{i, t}\left(1+R_{t}\right)\left(Q_{t-1} K_{i, t}-N_{i, t}\right) \\
& 1+R_{i, t}^{k}=\frac{X_{i, t}}{Q_{t-1}} \\
& C_{i, t}^{e}=\frac{1-\phi_{i}}{\phi_{i}} N_{i, t} \\
& C_{t}=(1-\lambda) C_{1, t}+\lambda C_{2, t}+C_{I, t}^{e}+C_{F, t}^{e}
\end{aligned}
$$

\section{B.2 Steady State}

$$
\begin{aligned}
\Pi & =\Pi_{I}=\Pi_{F}=Q=1 \\
1+R_{n} & =1+R=\frac{(1+g)^{1+(\sigma-1)(1-\varrho)}}{\beta} \\
P & =\left[\mathrm{w}\left(P_{F}\right)^{1-\mu}+(1-\mathrm{w})\left(P_{I}\right)^{1-\mu}\right]^{\frac{1}{1-\mu}}
\end{aligned}
$$




$$
\begin{aligned}
& \bar{Y}_{i, t}=\left(1-c_{i}\right)\left(N_{i} \bar{A}_{i, t}\right)^{\alpha_{i}} \bar{K}_{I, t}^{1-\alpha_{i}} ; i=F, I \\
& N_{F} \equiv(1-\lambda) n_{F} h_{1 F} \\
& N_{I} \equiv(1-\lambda)\left(1-n_{F}\right) h_{1 I}+\lambda h_{2 I} \\
& \frac{\varrho \bar{C}_{1, t}}{(1-\varrho) L_{F}\left(n_{F}+\left(1-n_{F}\right)\left(\frac{L_{1 F}}{L_{1 I}}\right)^{\varrho(\sigma-1)}\right)}=\bar{W}_{F, t} \\
& \frac{\varrho \bar{C}_{1, t}}{(1-\varrho) L_{1 I}\left(n_{F}\left(\frac{L_{1 I}}{L_{1 F}}\right)^{\varrho(\sigma-1)}+1-n_{F}\right)}=\bar{W}_{I, t} \\
& \frac{\varrho \bar{C}_{2, t}}{(1-\varrho) L_{2 I}\left(n_{F}\left(\frac{L_{2 I}}{L_{2 F}}\right)^{\varrho(\sigma-1)}+1-n_{F}\right)}=\bar{W}_{I, t} \\
& \bar{C}_{2, t}=h_{2 I} \bar{W}_{I, t} \\
& L_{1 i} \equiv 1-h_{1 i} ; i=I, F \\
& L_{2 I} \equiv 1-h_{2 I} \\
& \bar{C}_{t}=(1-\lambda) \bar{C}_{1, t}+\lambda \bar{C}_{2, t}+\bar{C}_{I, t}^{e}+\bar{C}_{F, t}^{e} \\
& \frac{\alpha_{i} P_{I}^{W} \bar{Y}_{i, t}^{W}}{P N_{i}}=\bar{W}_{i, t}+\bar{\tau}_{i, t} \equiv \bar{W}_{i, t}\left(1+\tau_{i, t}\right) ; i=F, I \\
& \left.\bar{W}_{F, t}=(1+r w) \bar{W}_{I, t}\right) \\
& \frac{P \bar{K}_{i, t}}{P_{i}^{W} \bar{Y}_{i, t}^{W}}=\frac{1-\alpha_{i}}{R_{i}+\delta} ; i=I, F \\
& \bar{I}_{t}=(\delta+g)\left(\bar{K}_{I, t}+\bar{K}_{F, t}\right) \\
& \bar{N}_{i, t}=\frac{\left(1-\phi_{i}\right) \bar{D}_{F, t}}{\left(1-\phi_{i}\left(1+R_{i}\right)\right)} ; i=I, F \\
& 1+R_{i}=(1+R) s_{i}\left(\frac{\bar{N}_{i, t}}{\bar{K}_{i, t}}\right) ; i=I, F \\
& \operatorname{PREM}_{i} \equiv R_{i}-R ; i=I, F \\
& Q=1 \\
& \bar{C}_{i, t}^{e}=\frac{1-\phi_{i}}{\phi_{i}} \bar{N}_{i, t} ; i=I, F \\
& \bar{Y}_{I, t}=\bar{C}_{I, t}=(1-\mathrm{w})\left(\frac{P_{I}}{P}\right)^{-\mu} \bar{C}_{t} \\
& \bar{Y}_{F, t}=\bar{C}_{F, t}+\bar{G}_{t}=\mathrm{w}\left(\frac{P_{F}}{P}\right)^{-\mu} \bar{C}_{t}+\bar{I}_{t}+\bar{G}_{t} \\
& \frac{P_{F}}{P} \bar{G}_{t}=n_{F} h_{F} \bar{\tau}_{F, t}+n_{I} h_{I} \bar{\tau}_{I, t} \\
& \bar{\tau}_{i, t}=\tau_{i} \bar{W}_{i, t} ; i=F, I \\
& \bar{\tau}_{I, t}=k \bar{\tau}_{F, t} \\
& P_{i}=\frac{1}{1-\frac{1}{\zeta_{i}}} P_{i}^{W} ; i=I, F
\end{aligned}
$$


where consumption, technical LAP, the real wage and tax rates, and government spending (all indicated by $\bar{X}_{t}$ ) are growing at a common growth rate.

There are three parameters $A_{F}, A_{I}$ and w that are dependent on the units chosen and therefore cannot be calibrated nor estimated. By choice of units of labour in both sectors, and units of capital and labour, we can normalize $A_{F}=A_{I}=1$. Then instead of estimating $\mathrm{w}$ for which we can have no priors we estimate a dimensionless quantity: the relative nominal outputs for the two sectors rel $_{Y}$. In terms of the endogenous steady state variable w we then have

$$
r e l_{Y}=\frac{P_{F} Y_{F}}{P_{I} Y_{I}}=\frac{\mathrm{w}\left(\frac{P_{F}}{P}\right)^{1-\mu} \bar{C}_{t}+\left(\frac{P_{F}}{P}\right)\left(\bar{I}_{t}+\bar{G}_{t}\right)}{(1-\mathrm{w})\left(\frac{P_{I}}{P}\right)^{1-\mu} \bar{C}_{t}}
$$

From (B.1) we can solve for w to obtain

$$
\mathrm{w}=\frac{\operatorname{rel}_{Y}\left(\frac{P_{I}}{P}\right)^{1-\mu} \bar{C}_{t}-\left(\frac{P_{F}}{P}\right)\left(\bar{I}_{t}+\bar{G}_{t}\right)}{\left(\frac{P_{F}}{P}\right)^{1-\mu} \bar{C}_{t}+r e l_{Y}\left(\frac{P_{I}}{P}\right)^{1-\mu} \bar{C}_{t}}
$$

so we can solve for $\mathrm{w}$ as a post-recursive variable. This completes the specification of the model which now includes $r e l_{Y}$ as a parameter to be estimated, which has been switched with $\mathrm{w}$ which is now an endogenous variable in the steady state.

We can also use data for the the relative numbers of workers employed in the formal sector $\mathrm{rel}_{n}$ given in the model by

$$
r e l_{n}=\frac{(1-\lambda) n_{F}}{(1-\lambda)\left(1-n_{F}\right)+\lambda}
$$

From Marjit and Kar (2008) we learn that in $200180 \%$ workers in industry were informal and they contributed $28 \%$ to GDP. This implies rel $_{n}=0.25$ and rel $_{Y}=2.6$ implying a formal-informal labour productivity ratio of around 10:1. Sen and Kolli (2009) suggest estimates $r e l_{n}=0.1$ and $r e l_{Y}=1.1$ implying a slightly higher productivity ratio 1:11. Rada (2009) provide estimates $r e l_{n}=0.075$. rel $_{Y}=0.68$ implying a slightly lower productivity ratio $1: 9 .^{16}$

The question is: how can the model be calibrated to reproduce this high productivity gap? There are two parameters we can vary that increase the size of the informal sector and reduce its marginal product of labour: the mark-up of the real wage in the formal sector over that in the informal sector, $r w$, and labour shares in production, $\alpha_{I}$ and $\alpha_{I}$. Figure 2 puts $\alpha_{F}=0.6<\alpha_{I}=0.8$ and varies $r w$, Figure 3 puts $\alpha_{F}=0.5<\alpha_{I}=0.8$ and again

\footnotetext{
${ }^{16}$ This productivity gap seems very high. Ila Patnaik has pointed out that the informal sector employment numbers may be exaggerated as they include all household members, employed or otherwise, in the household sector. As a first attempt we therefore choose priors rel $_{n}=0.2$, rel $_{Y}=1$ implying a productivity ratio of 1:5.
} 
varies $r w$. If we take $r e l_{n}=0.2$ we have three possibilities to hit this value: for $\alpha_{F}=0.6$, $r e l_{Y}=1.0$ and $r w=0.75$; for $\alpha_{F}=0.5$ either $\operatorname{rel}_{Y}=1.0$ and $r w=0.47$ or $\operatorname{rel}_{Y}=1.5$ and $r w=0.9$. In the estimation we choose priors of $r w=0.75$, rel $_{Y}=1.0, \alpha_{F}=0.6$ and $\alpha_{I}=0.8$.

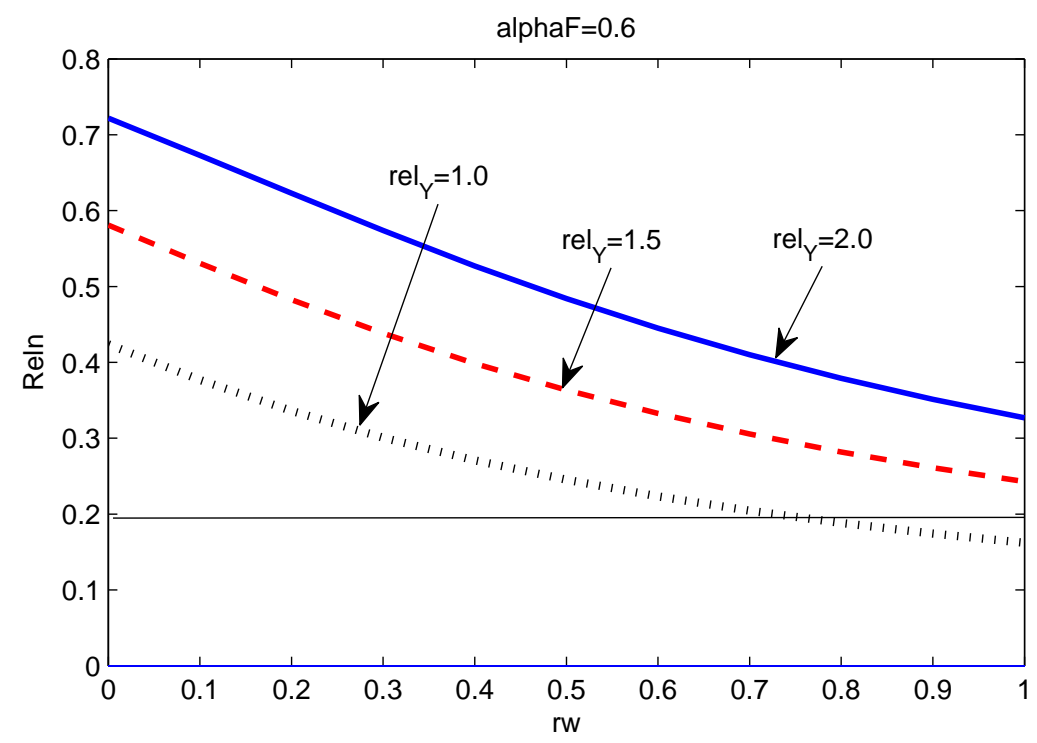

Figure 2: Calibration of $r w$ to Fit $r e l_{n} . \alpha_{F}=0.6$

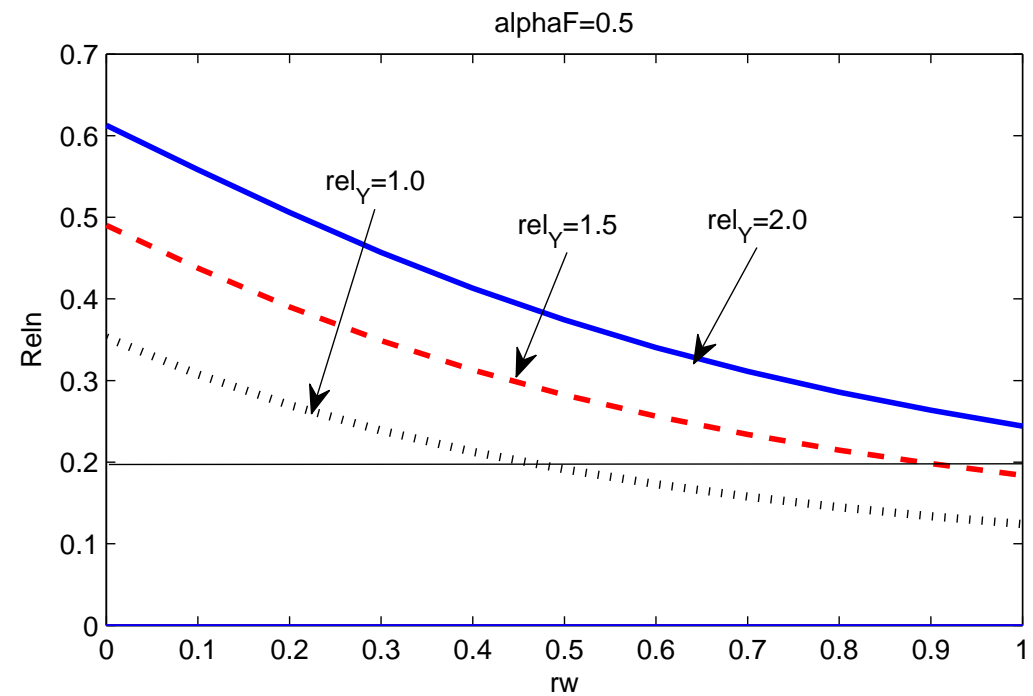

Figure 3: Calibration of $r w$ TO Fit $r e l_{n} . \alpha_{F}=0.5$ 


\section{Tables and Figures}

\begin{tabular}{lcc|c}
\hline \hline Calibrated parameter & Symbol & Value for India & Value for US \\
Discount factor & $\beta$ & 0.9823 & 0.99 \\
Depreciation rate & $\delta$ & 0.025 & 0.025 \\
Formal sector FA risk premium & $\Theta_{F}$ & 1.012 & - \\
Informal sector FA risk premium & $\Theta_{I}$ & 1.06 & - \\
Investment adjustment cost parameter & $\phi_{X}$ & 2.00 & 2.00 \\
\hline \hline
\end{tabular}

TABLE 1: Calibrated Parameters

\begin{tabular}{|c|c|c|c|c|c|}
\hline \multirow[t]{2}{*}{ Parameter } & \multirow[t]{2}{*}{ Notation } & \multicolumn{3}{|c|}{ Prior distribution } & \multirow{2}{*}{$\begin{array}{c}\text { Posterior distribution } \\
\text { NK Model }{ }^{\diamond}\end{array}$} \\
\hline & & Density & Mean & S.D/df & \\
\hline Risk aversion & $\sigma$ & Normal & 1.50 & 0.375 & $1.85[1.31: 2.33]$ \\
\hline Calvo prices & $\xi$ & Beta & 0.50 & 0.10 & $0.67[0.61: 0.74]$ \\
\hline Labour share & $\alpha$ & Normal & 0.70 & 0.05 & $0.58[0.52: 0.64]$ \\
\hline Preference parameter & $\varrho$ & Beta & 0.50 & 0.15 & $0.79[0.70: 0.88]$ \\
\hline Substitution elasticity (varieties) & $\zeta$ & Normal & 7.00 & 0.50 & $7.17[6.40: 8.02]$ \\
\hline \multicolumn{6}{|l|}{ Interest rate rule } \\
\hline Interest rate smoothing & $\rho$ & Beta & 0.75 & 0.10 & $0.60[0.55: 0.66]$ \\
\hline Feedback from expected inflation & $\theta$ & Normal & 1.50 & 0.25 & $1.44[1.06: 1.77]$ \\
\hline Feedback from past inflation & $\phi$ & Normal & 0.50 & 0.05 & $0.45[0.37: 0.53]$ \\
\hline Degree of forward-lookingness & $\varphi$ & Beta & 0.50 & 0.20 & $0.93[0.89: 0.97]$ \\
\hline Degree of backward-lookingness & $\tau$ & Beta & 0.50 & 0.20 & $0.11[0.02: 0.19]$ \\
\hline \multicolumn{6}{|l|}{$\mathrm{AR}(1)$ coefficient } \\
\hline Technology & $\rho_{A}$ & Beta & 0.50 & 0.20 & $0.65[0.43: 0.85]$ \\
\hline Government spending & $\rho_{G}$ & Beta & 0.50 & 0.20 & $0.92[0.89: 0.95]$ \\
\hline Price mark-up & $\rho_{M S}$ & Beta & 0.50 & 0.20 & $0.92[0.88: 0.96]$ \\
\hline Risk premium & $\rho_{R P S}$ & Beta & 0.50 & 0.20 & $0.70[0.65: 0.77]$ \\
\hline \multicolumn{6}{|c|}{ Standard deviation of AR(1) innovations/I.I.D. shocks } \\
\hline Technology & $s d\left(\epsilon_{A}\right)$ & Inv. gamma & 0.10 & 2.00 & $0.09[0.02: 0.15]$ \\
\hline Government spending & $s d\left(\epsilon_{G}\right)$ & Inv. gamma & 0.50 & 2.00 & $3.72[3.44: 4.00]$ \\
\hline Price mark-up & $s d\left(\epsilon_{M S}\right)$ & Inv. gamma & 1.16 & 2.00 & $1.53[1.16: 1.92]$ \\
\hline Risk premium & $s d\left(\epsilon_{R P S}\right)$ & Inv. gamma & 0.10 & 2.00 & $2.10[1.31: 2.85]$ \\
\hline Monetary policy & $s d\left(\epsilon_{M P S}\right)$ & Inv. gamma & 0.10 & 2.00 & $0.25[0.22: 0.28]$ \\
\hline Price contract length & $\frac{1}{1-\xi}$ & & & & 2.56 \\
\hline
\end{tabular}

TABle 2: Priors and Posterior Estimates - US Economy

$\diamond$ Notes: we report posterior means and 95\% probability intervals (in parentheses) based on the output of the Metropolis-Hastings Algorithm. Sample range: 1980:I to 2006:IV. 


\begin{tabular}{|c|c|c|c|c|c|c|c|}
\hline \multirow[t]{2}{*}{ Parameter } & \multirow[t]{2}{*}{ Notation } & \multicolumn{3}{|c|}{ Prior distribution } & \multicolumn{3}{|c|}{ 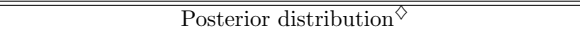 } \\
\hline & & Density & Mean & S.D $/ \mathrm{df}$ & NK Model & NK Model with FA & 2-sector NK Model \\
\hline Risk aversion & $\sigma$ & Normal & 2.00 & 0.50 & $2.14[1.40: 2.92]$ & $1.62[0.74: 2.43]$ & $1.99[1.33: 2.69]$ \\
\hline Calvo prices $(\mathrm{F})^{\mathbf{2}}$ & $\xi_{F}$ & Beta & 0.75 & 0.15 & $0.57[0.45: 0.69]$ & $0.39[0.26: 0.51]$ & $0.75[0.57: 0.95]$ \\
\hline Calvo prices (I) & $\xi_{I}$ & Beta & 0.75 & 0.15 & - & - & $0.30[0.15: 0.43]$ \\
\hline Labour share $(\mathrm{F})$ & $\alpha_{F}$ & Beta & 0.60 & 0.10 & - & - & $0.68[0.60: 0.76]$ \\
\hline Labour share (I) & $\alpha / \alpha_{I}$ & Beta & 0.80 & 0.10 & $0.62[0.47: 0.76]$ & $0.78[0.69: 0.88]$ & $0.74[0.61: 0.87]$ \\
\hline Preference parameter & $\varrho$ & Beta & 0.50 & 0.20 & $0.40[0.22: 0.58]$ & $0.25[0.12: 0.37]$ & $0.22[0.10: 0.31]$ \\
\hline Substitution elasticity (varieties, F) & $\zeta_{F}$ & Normal & 7.00 & 0.50 & $7.01[6.17: 7.79]$ & $6.96[6.12: 7.75]$ & $7.02[6.21: 7.81]$ \\
\hline Substitution elasticity (varieties, I) & $\zeta_{I}$ & Normal & 7.00 & 0.50 & - & - & $7.00[6.17: 7.82]$ \\
\hline Substitution Elasticity (F/I goods) & $\mu$ & Normal & 1.50 & 0.20 & - & - & $1.45[1.13: 1.76]$ \\
\hline Degree of Labour market frictions & & Beta & 0.75 & 0.10 & - & - & $0.78[0.64: 0.92]$ \\
\hline GDP Contribution & $\operatorname{rel}_{Y} \equiv \frac{P_{F} Y_{F}}{P_{I} Y_{I}}$ & Normal & 1.00 & 0.50 & - & - & $1.15[0.67: 1.64]$ \\
\hline \multicolumn{8}{|l|}{ Financial accelerator/RT consumers } \\
\hline External finance premium elasticity (F) & $\chi_{F}$ & Inv. gamma & 0.05 & 4.00 & - & $0.03[0.01: 0.05]$ & $0.05[0.01: 0.10]$ \\
\hline External finance premium elasticity (I) & $\chi_{I}$ & Inv. gamma & 0.05 & 4.00 & - & - & $0.03[0.01: 0.05]$ \\
\hline Inverse of Leverage $(\mathrm{F})$ & $n_{k_{F}}$ & Beta & 0.50 & 0.15 & - & $0.58[0.41: 0.74]$ & $0.53[0.29: 0.75]$ \\
\hline Inverse of Leverage (I) & $n_{k_{I}}$ & Beta & 0.50 & 0.15 & - & - & $0.61[0.39: 0.81]$ \\
\hline Entrepreneurs survival rate $(\mathrm{F})$ & $\xi_{e_{F}}$ & Beta & 0.93 & 0.05 & - & $0.93[0.88: 0.96]$ & $0.90[0.88: 0.98]$ \\
\hline Entrepreneurs survival rate (I) & $\xi_{e_{I}}$ & Beta & 0.93 & 0.05 & - & - & $0.89[0.84: 0.95]$ \\
\hline Proportion of RT consumers & $\lambda$ & Beta & 0.40 & 0.10 & - & $0.21[0.11: 0.29]$ & $0.30[0.19: 0.43]$ \\
\hline \multicolumn{8}{|l|}{ Interest rate rule } \\
\hline Interest rate smoothing & $\rho$ & Beta & 0.75 & 0.10 & $0.81[0.70: 0.92]$ & $0.79[0.66: 0.92]$ & $0.80[0.68: 0.93]$ \\
\hline Feedback from expected inflation & $\theta$ & Normal & 2.00 & 1.00 & $1.64[0.31: 3.14]$ & $2.42[0.83: 3.89]$ & $2.40[1.09: 3.53]$ \\
\hline Feedback from past inflation & $\phi$ & Normal & 2.00 & 1.00 & $0.52[-0.09: 1.14]$ & $1.64[0.48: 2.86]$ & $1.00[0.15: 1.76]$ \\
\hline Degree of forward-lookingness & $\varphi$ & Beta & 0.50 & 0.20 & $0.51[0.17: 0.83]$ & $0.42[0.13: 0.72]$ & $0.50[0.21: 0.78]$ \\
\hline Degree of backward-lookingness & $\tau$ & Beta & 0.50 & 0.20 & $0.47[0.10: 0.86]$ & $0.46[0.11: 0.84]$ & $0.50[0.15: 0.88]$ \\
\hline \multicolumn{8}{|l|}{$\mathrm{AR}(1)$ coefficient } \\
\hline Technology (F) & $\rho_{A_{F}}$ & Beta & 0.75 & 0.10 & $0.60[0.46: 0.74]$ & $0.73[0.61: 0.85]$ & $0.72[0.58: 0.88]$ \\
\hline Technology (I) & $\rho_{A_{I}}$ & Beta & 0.75 & 0.10 & - & - & $0.70[0.56: 0.84]$ \\
\hline Government spending & $\rho_{G}$ & Beta & 0.75 & 0.10 & $0.66[0.56: 0.77]$ & $0.82[0.71: 0.92]$ & $0.79[0.81: 0.87]$ \\
\hline Price mark-up (F) & $\rho_{M S_{F}}$ & Beta & 0.75 & 0.10 & $0.69[0.52: 0.87]$ & $0.68[0.53: 0.83]$ & $0.73[0.57: 0.89]$ \\
\hline Price mark-up (I) & $\rho_{M S_{I}}$ & Beta & 0.75 & 0.10 & - & - & $0.74[0.59: 0.91]$ \\
\hline Risk premium & $\rho_{R P S}$ & Beta & 0.75 & 0.10 & $0.67[0.58: 0.75]$ & $0.78[0.70: 0.86]$ & $0.78[0.69: 0.87]$ \\
\hline \multicolumn{8}{|c|}{ Standard deviation of $\mathrm{AR}(1)$ innovations/I.I.D. shocks } \\
\hline Technology (F) & $s d\left(\epsilon_{A_{F}}\right)$ & Inv. gamma & 3.00 & 3.00 & $1.78[1.08: 2.46]$ & $1.21[0.90: 1.51]$ & $2.09[1.07: 3.21]$ \\
\hline Technology (I) & $s d\left(\epsilon_{A_{I}}\right)$ & Inv. gamma & 3.00 & 3.00 & - & - & $1.61[1.13: 2.12]$ \\
\hline Government spending & $s d\left(\epsilon_{G}\right)$ & Inv. gamma & 3.00 & 3.00 & $7.01[4.87: 9.17]$ & $5.78[1.12: 9.77]$ & $21.09[17.19: 25.00]$ \\
\hline Price mark-up (F) & $s d\left(\epsilon_{M S_{F}}\right)$ & Inv. gamma & 3.00 & 3.00 & $2.66[0.97: 4.53]$ & $4.87[1.21: 8.31]$ & $2.11[1.01: 3.25]$ \\
\hline Price mark-up (I) & $s d\left(\epsilon_{M S_{I}}\right)$ & Inv. gamma & 3.00 & 3.00 & - & - & $2.07[0.99: 3.16]$ \\
\hline Risk premium & $s d\left(\epsilon_{R P S}\right)$ & Inv. gamma & 3.50 & 3.00 & $3.93[1.95: 5.89]$ & $1.94[1.28: 2.56]$ & $1.99[1.30: 2.66]$ \\
\hline Monetary policy & $s d\left(\epsilon_{M P S}\right)$ & Inv. gamma & 3.00 & 3.00 & $1.38[0.95: 1.80]$ & $2.77[1.52: 4.03]$ & $1.96[1.12: 2.76]$ \\
\hline Employment ratio* & $r e l_{n} \equiv \frac{(1-\lambda) n_{F}}{(1-\lambda)\left(1-n_{F}\right)+\lambda}$ & n.a. & 0.20 & n.a. & - & - & $0.28[0.22: 0.35]$ \\
\hline Price contract length (F) & $\frac{1}{1-\xi_{F}}$ & & & & 2.38 & 1.67 & 4.02 \\
\hline Price contract length (I) & $\frac{1}{1-\xi_{I}}$ & & & & - & - & 1.43 \\
\hline Weight on formality & $w \equiv \frac{\operatorname{rel}_{Y}\left(\frac{P_{I}}{P}\right)^{1-\mu} \bar{C}_{t}-\left(\frac{P_{F}}{P}\right)\left(\bar{I}_{t}+\bar{G}_{t}\right)}{\left(\frac{P_{F}}{P}\right)^{1-\mu} \bar{C}_{t}+r e l_{Y}\left(\frac{P_{I}}{P}\right)^{1-\mu} \bar{C}_{t}}$ & & & & - & - & 0.30 \\
\hline LL & & & & & -358.95 & -356.28 & -350.73 \\
\hline Prob. & & & & & 0.0003 & 0.0039 & 0.9959 \\
\hline
\end{tabular}

TABle 3: Priors and Posterior Estimates - Indian Economy

$\diamond$ Notes: we report posterior means and $95 \%$ probability intervals (in parentheses) based on the output of the Metropolis-Hastings Algorithm. Sample range: 1996:I to 2008:IV.

$\mathrm{F}=$ formal sector; $\mathrm{I}=$ informal sector.

* The employment ratio $r e l_{n}$ has an unknown distribution and the estimated $n_{F}=0.3153$. 


\begin{tabular}{|c|c|c|c|c|}
\hline \multicolumn{5}{|c|}{ Standard Deviation } \\
\hline Model & Output & Inflation & Interest rate & Investment \\
\hline Data & 2.06 & 0.48 & 0.92 & 8.47 \\
\hline NK Model & 2.87 & 0.38 & 0.64 & 8.51 \\
\hline \multicolumn{5}{|c|}{ Cross-correlation with Output } \\
\hline Data & 1.00 & -0.02 & 0.14 & 0.56 \\
\hline NK Model & 1.00 & 0.38 & 0.40 & 0.73 \\
\hline \multicolumn{5}{|c|}{ Autocorrelations (Order $=1$ ) } \\
\hline Data & 0.91 & 0.85 & 0.94 & 0.95 \\
\hline NK Model & 0.96 & 0.70 & 0.91 & 0.96 \\
\hline
\end{tabular}

Table 4: Selected Second Moments - US Economy ${ }^{\diamond}$

$\diamond$ All the second moments are theoretical moments computed from the model solutions (order of approximation $=1$ ). The results are based on the models' posterior distribution.

\begin{tabular}{lcccc}
\hline \hline \multirow{5}{*}{ Model } & Standard Deviation & \\
& Output & Inflation & Interest rate & Investment \\
\hline Data & 1.22 & 0.97 & 1.93 & 5.30 \\
NK Model & 2.02 & 1.04 & 1.41 & 7.59 \\
NK Model with FA & 2.42 & 1.02 & 1.76 & 8.37 \\
2-sector NK Model & $\mathbf{1 . 5 9}$ & $\mathbf{0 . 9 7}$ & $\mathbf{1 . 8 4}$ & $\mathbf{7 . 8 0}$ \\
\hline \hline \multicolumn{5}{c}{ Cross-correlation with Output } \\
Data & 1.00 & 0.11 & 0.32 & 0.42 \\
NK Model 1 & 1.00 & 0.27 & 0.05 & 0.50 \\
NK Model with FA & 1.00 & 0.14 & 0.44 & 0.46 \\
2-sector NK Model & $\mathbf{1 . 0 0}$ & $\mathbf{0 . 1 8}$ & $\mathbf{0 . 3 1}$ & $\mathbf{0 . 2 9}$ \\
\hline \hline \multicolumn{5}{c}{ Autocorrelations (Order=1) } \\
Data & 0.44 & 0.13 & 0.83 & 0.88 \\
NK Model & 0.74 & 0.05 & 0.71 & 0.96 \\
NK Model with FA & 0.79 & -0.23 & 0.82 & 0.96 \\
2-sector NK Model & $\mathbf{0 . 7 0}$ & $\mathbf{- 0 . 1 1}$ & $\mathbf{0 . 8 8}$ & $\mathbf{0 . 9 3}$ \\
\hline \hline
\end{tabular}

Table 5: Selected Second Moments - Indian Economy 


\begin{tabular}{|c|c|c|c|c|c|c|}
\hline \multirow[b]{2}{*}{$\begin{array}{l}\text { Forecast } \\
\text { horizon }\end{array}$} & \multirow[b]{2}{*}{$\begin{array}{l}\text { Observable } \\
\text { variables }\end{array}$} & \multicolumn{5}{|c|}{ Shocks of the Estimated DSGE Model } \\
\hline & & Productivity & $\begin{array}{c}\text { Government } \\
\text { spending }\end{array}$ & $\begin{array}{c}\text { Monetary } \\
\text { policy }\end{array}$ & $\begin{array}{c}\text { Price } \\
\text { Mark-up }\end{array}$ & $\begin{array}{c}\text { Risk } \\
\text { premium }\end{array}$ \\
\hline \multirow[t]{4}{*}{$\mathrm{t}=1$} & Inflation & 23.3 & 28.4 & 42.3 & 5.8 & 0.3 \\
\hline & Output & 14.9 & 50.0 & 11.6 & 22.9 & 0.5 \\
\hline & Interest rate & 29.6 & 37.2 & 25.9 & 7.3 & 0.0 \\
\hline & Investment & 6.3 & 9.3 & 0.3 & 2.3 & 81.8 \\
\hline \multirow[t]{4}{*}{$\mathrm{t}=4$} & Inflation & 23.1 & 27.8 & 40.5 & 5.8 & 2.8 \\
\hline & Output & 26.1 & 28.6 & 6.2 & 26.0 & 13.0 \\
\hline & Interest rate & 28.6 & 39.2 & 13.6 & 6.8 & 11.8 \\
\hline & Investment & 6.5 & 10.8 & 0.1 & 2.4 & 80.3 \\
\hline \multirow[t]{4}{*}{$\mathrm{t}=10$} & Inflation & 23.1 & 27.8 & 40.4 & 5.8 & 2.9 \\
\hline & Output & 24.5 & 24.4 & 5.1 & 23.3 & 22.6 \\
\hline & Interest rate & 24.9 & 34.2 & 11.7 & 5.9 & 23.2 \\
\hline & Investment & 6.2 & 11.2 & 0.1 & 2.3 & 80.1 \\
\hline \multirow[t]{4}{*}{$\mathrm{t}=100$} & Inflation & 23.1 & 27.8 & 40.4 & 5.78 & 2.9 \\
\hline & Output & 21.5 & 22.3 & 4.3 & 19.9 & 32.0 \\
\hline & Interest rate & 24.8 & 34.0 & 11.6 & 5.9 & 23.7 \\
\hline & Investment & 6.2 & 11.2 & 0.1 & 2.3 & 80.2 \\
\hline
\end{tabular}

Table 6: Forecast Error Variance Decomposition - NK Model (in Percent)

\begin{tabular}{llccccc}
\hline \hline \multirow{2}{*}{$\begin{array}{l}\text { Forecast } \\
\text { horizon }\end{array}$} & Observable & Productivity & $\begin{array}{c}\text { Shocks of the Estimated DSGE Model } \\
\text { Government } \\
\text { spending }\end{array}$ & $\begin{array}{c}\text { Monetary } \\
\text { policy }\end{array}$ & $\begin{array}{c}\text { Price } \\
\text { Mark-up }\end{array}$ & $\begin{array}{c}\text { Risk } \\
\text { premium }\end{array}$ \\
\hline \multirow{3}{*}{$\mathrm{t}=1$} & & & & & & \\
& Inflation & 4.2 & 2.5 & 85.8 & 2.5 & 4.9 \\
& Output & 30.8 & 1.1 & 2.4 & 54.7 & 11.0 \\
& Interest rate & 28.1 & 17.1 & 0.1 & 16.7 & 38.0 \\
& Investment & 13.6 & 11.7 & 0.1 & 0.6 & 74.0 \\
& & & & & & \\
$\mathrm{t}=4$ & Inflation & 4.7 & 2.7 & 85.3 & 2.7 & 4.6 \\
& Output & 34.9 & 0.7 & 1.3 & 47.4 & 15.8 \\
& Interest rate & 19.1 & 13.1 & 0.2 & 12.1 & 55.5 \\
& Investment & 11.4 & 11.7 & 0.0 & 0.5 & 76.4 \\
$\mathrm{t}=10$ & & & & & \\
& Inflation & 4.7 & 2.7 & 85.3 & 2.7 & 4.6 \\
& Output & 33.2 & 0.7 & 1.1 & 41.5 & 23.4 \\
& Interest rate & 14.5 & 10.2 & 0.2 & 9.6 & 65.5 \\
& Investment & 9.6 & 11.8 & 0.0 & 0.4 & 78.1 \\
& & & & & \\
$\mathrm{t}=100$ & Inflation & 4.7 & 2.7 & 85.3 & 2.7 & 4.6 \\
& Output & 30.0 & 1.0 & 1.1 & 36.8 & 31.0 \\
& Interest rate & 13.8 & 9.8 & 0.2 & 9.5 & 66.7 \\
& Investment & 9.4 & 11.8 & 0.0 & 0.4 & 78.4 \\
\hline \hline
\end{tabular}

Table 7: Forecast Error Variance Decomposition - NK Model with FA (in PERCENT) 


\begin{tabular}{|c|c|c|c|c|c|c|c|c|}
\hline \multirow[b]{2}{*}{$\begin{array}{l}\text { Forecast } \\
\text { horizon }\end{array}$} & \multirow[b]{2}{*}{$\begin{array}{l}\text { Observable } \\
\text { variables }\end{array}$} & \multicolumn{7}{|c|}{$\begin{array}{l}\text { Shocks of the Estimated DSGE Model } \\
\end{array}$} \\
\hline & & $\begin{array}{c}\text { Productivity } \\
(\mathrm{F})\end{array}$ & $\begin{array}{l}\text { Productivity } \\
\text { (I) }\end{array}$ & $\begin{array}{c}\text { Government } \\
\text { spending }\end{array}$ & $\begin{array}{c}\text { Monetary } \\
\text { policy }\end{array}$ & $\begin{array}{l}\text { Mark-up } \\
(\mathrm{F})\end{array}$ & $\begin{array}{l}\text { Mark-up } \\
\text { (I) }\end{array}$ & $\begin{array}{c}\text { Risk } \\
\text { premium }\end{array}$ \\
\hline \multirow[t]{4}{*}{$\mathrm{t}=1$} & Inflation & 0.1 & 7.3 & 7.0 & 74.7 & 0.0 & 0.8 & 10.1 \\
\hline & Output & 3.1 & 47.5 & 34.4 & 3.2 & 0.0 & 3.2 & 8.7 \\
\hline & Interest rate & 0.6 & 19.9 & 25.5 & 5.3 & 0.0 & 2.1 & 46.5 \\
\hline & Investment & 1.2 & 8.2 & 22.1 & 0.4 & 0.0 & 0.1 & 68.0 \\
\hline \multirow[t]{4}{*}{$\mathrm{t}=4$} & Inflation & 0.2 & 9.0 & 6.9 & 72.7 & 0.0 & 1.1 & 10.1 \\
\hline & Output & 6.7 & 52.9 & 24.3 & 1.9 & 0.0 & 6.7 & 7.5 \\
\hline & Interest rate & 0.8 & 7.4 & 20.7 & 2.0 & 0.0 & 0.8 & 68.5 \\
\hline & Investment & 1.4 & 5.9 & 28.1 & 0.4 & 0.1 & 0.1 & 65.0 \\
\hline \multirow[t]{4}{*}{$\mathrm{t}=10$} & Inflation & 0.2 & 9.0 & 6.9 & 72.66 & 0.0 & 1.1 & 10.1 \\
\hline & Output & 7.4 & 48.9 & 21.5 & 1.7 & 0.0 & 7.1 & 13.4 \\
\hline & Interest rate & 0.6 & 5.2 & 16.5 & 1.6 & 0.0 & 0.7 & 75.4 \\
\hline & Investment & 1.5 & 4.3 & 34.6 & 0.4 & 0.1 & 0.1 & 59.0 \\
\hline \multirow[t]{4}{*}{$t=100$} & Inflation & 0.2 & 9.0 & 6.9 & 72.7 & 0.0 & 1.1 & 10.1 \\
\hline & Output & 6.9 & 43.5 & 23.4 & 1.7 & 0.1 & 6.4 & 18.1 \\
\hline & Interest rate & 0.5 & 4.9 & 15.6 & 1.9 & 0.0 & 0.8 & 76.3 \\
\hline & Investment & 1.5 & 4.3 & 35.0 & 0.5 & 0.2 & 0.2 & 58.3 \\
\hline
\end{tabular}

Table 8: Forecast Error Variance Decomposition - 2 Sector NK Model (in PerCent) $)^{\diamond}$

$\diamond$ All the variance decomposition is computed from the model solutions (order of approximation = 1). The results are based on the models' posterior distribution. 

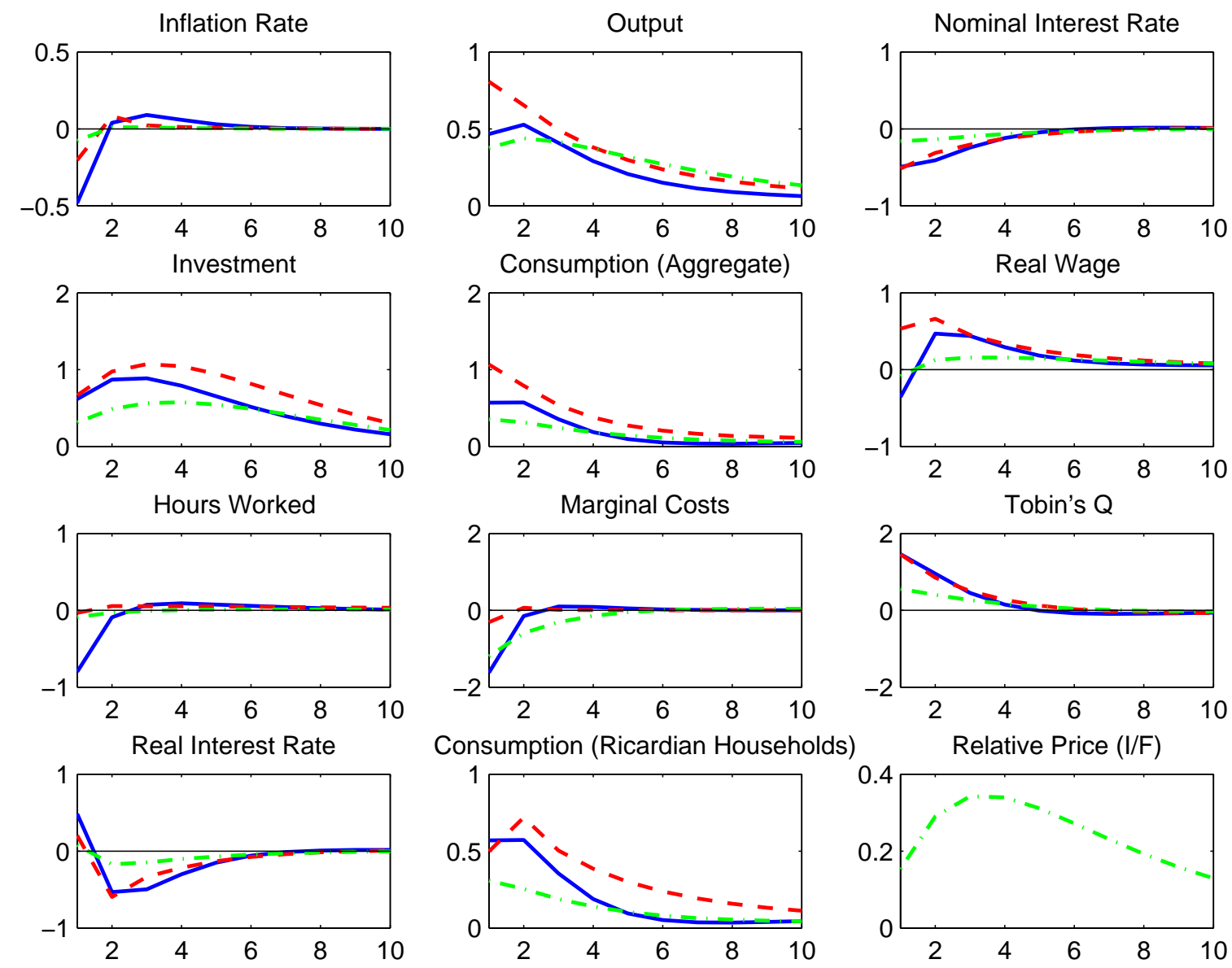

NK Model - - - NK Model with FA : - : , 2-sector NK Model

\section{Figure 4: Estimated Impulse Responses to a Productivity Shock $\diamond$}

$\diamond$ Each panel plots the mean response corresponding a positive one standard deviation shock. Each response is for a 10 quarters (2.5 years) horizon. All DSGE impulse responses are computed simulating the vector of DSGE model parameters at the posterior mean values reported in Table 3 . 

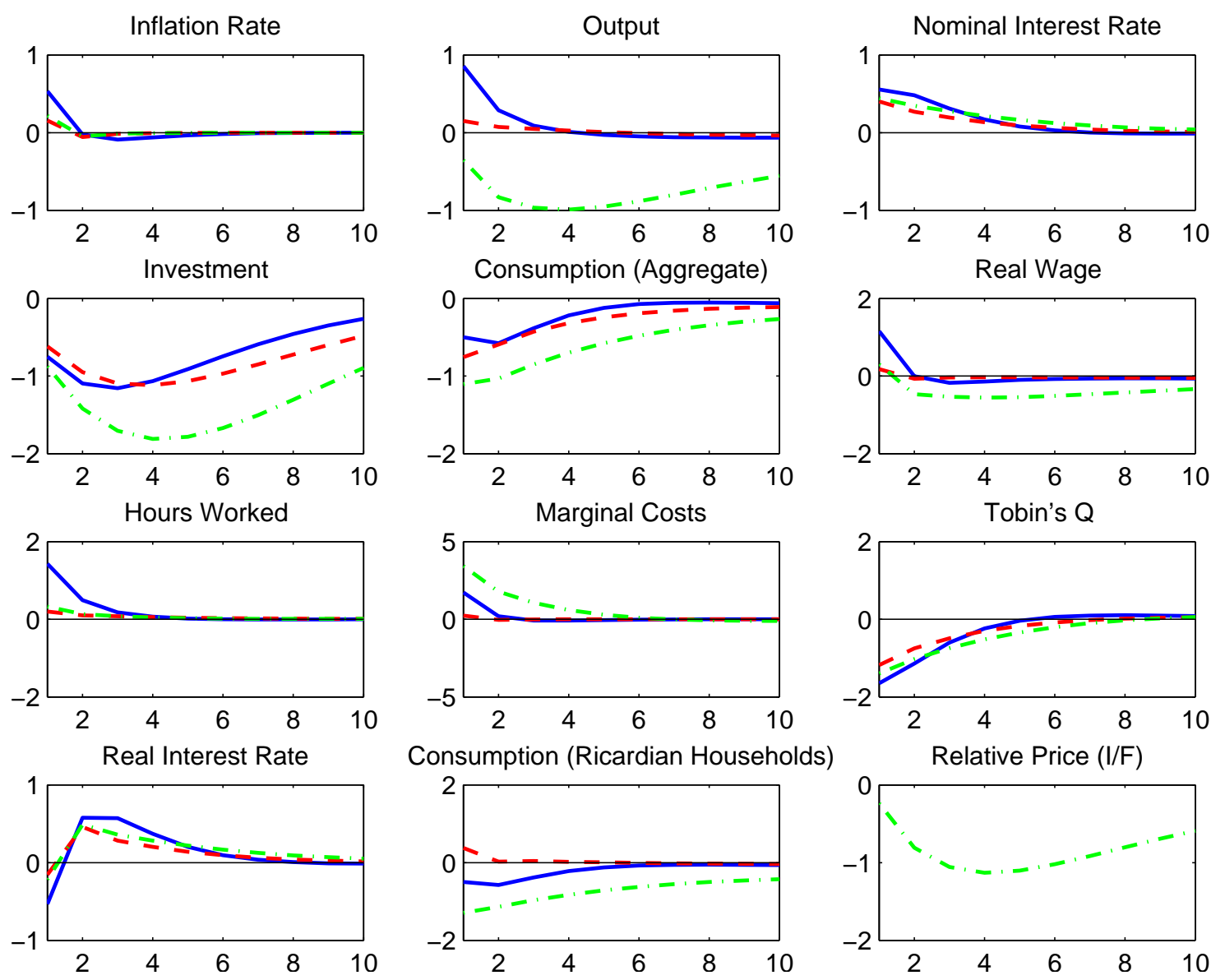

Figure 5: Estimated Impulse Responses to a Government Spending Shock 

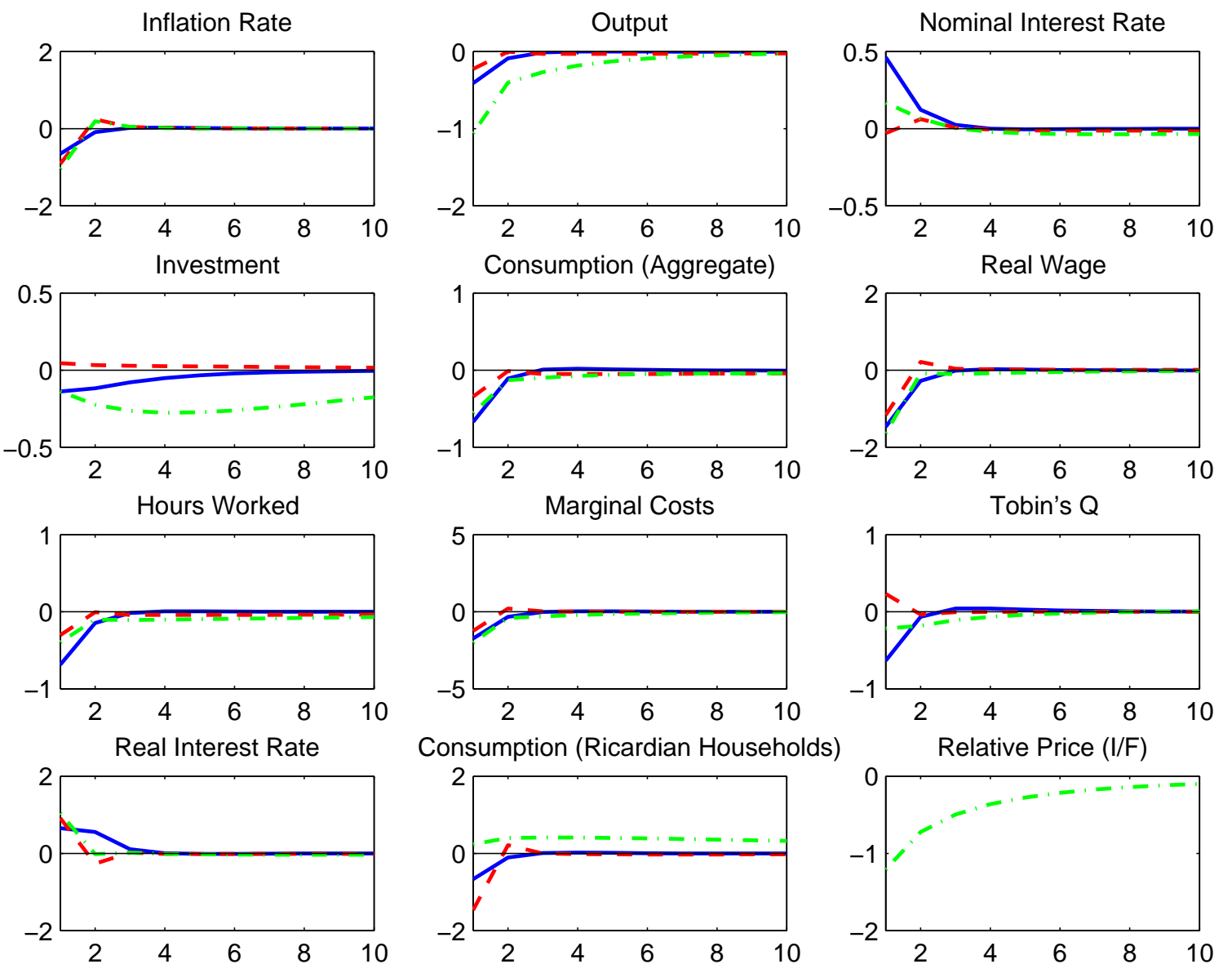

Figure 6: Estimated Impulse Responses to a Monetary Policy Shock 

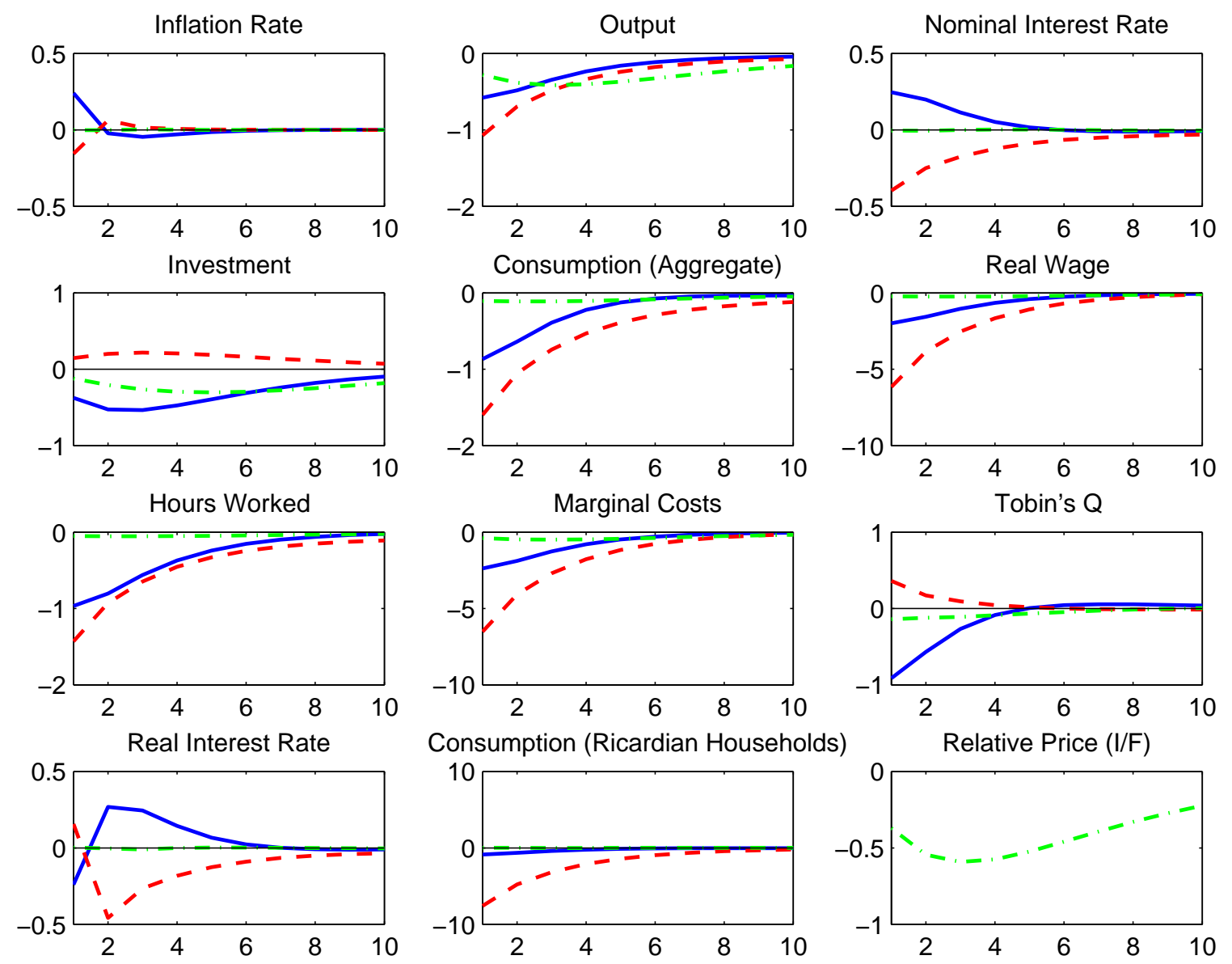

Figure 7: Estimated Impulse Responses to a Price Mark-up Shock 

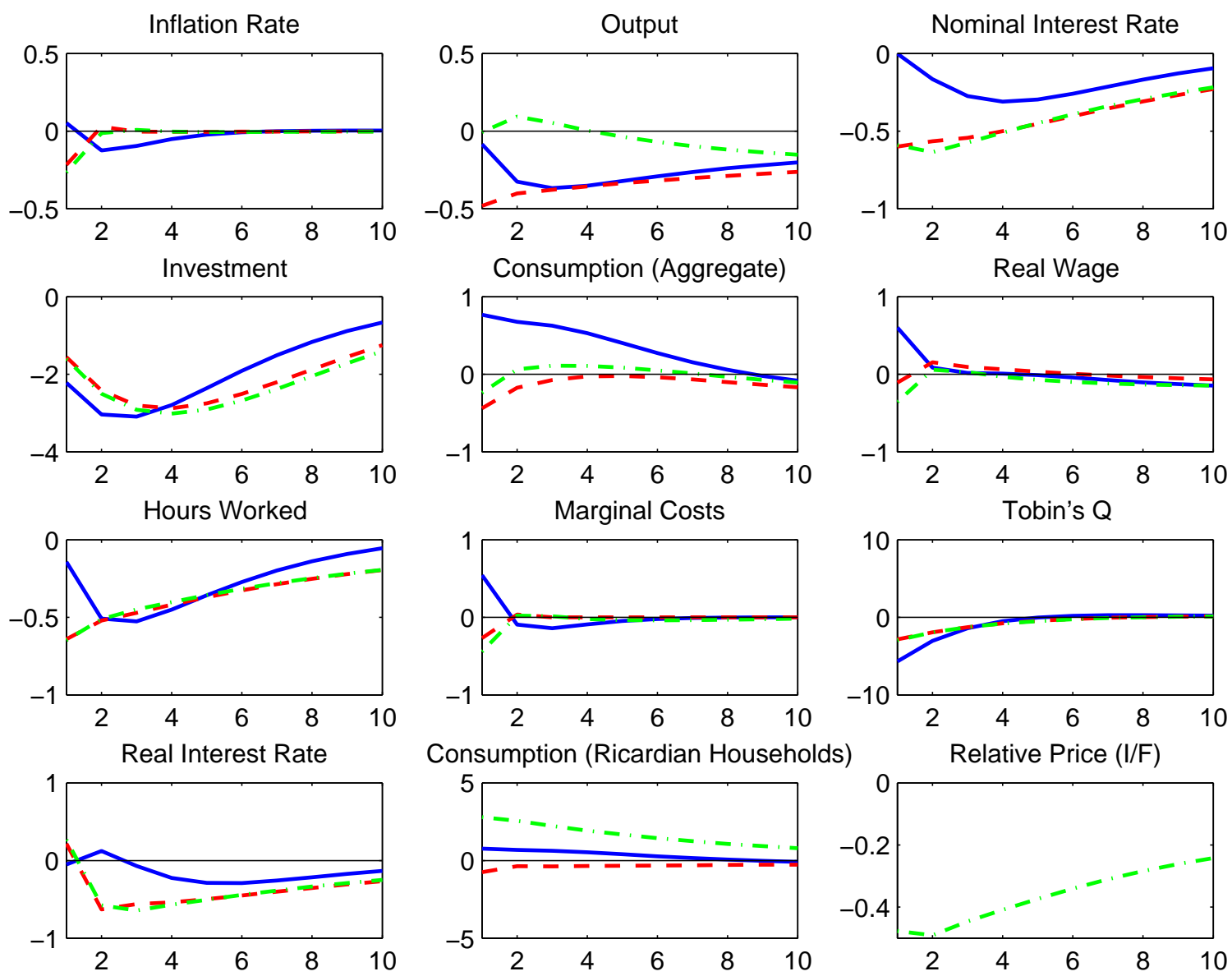

Figure 8: Estimated Impulse Responses to a Risk Premium Shock 

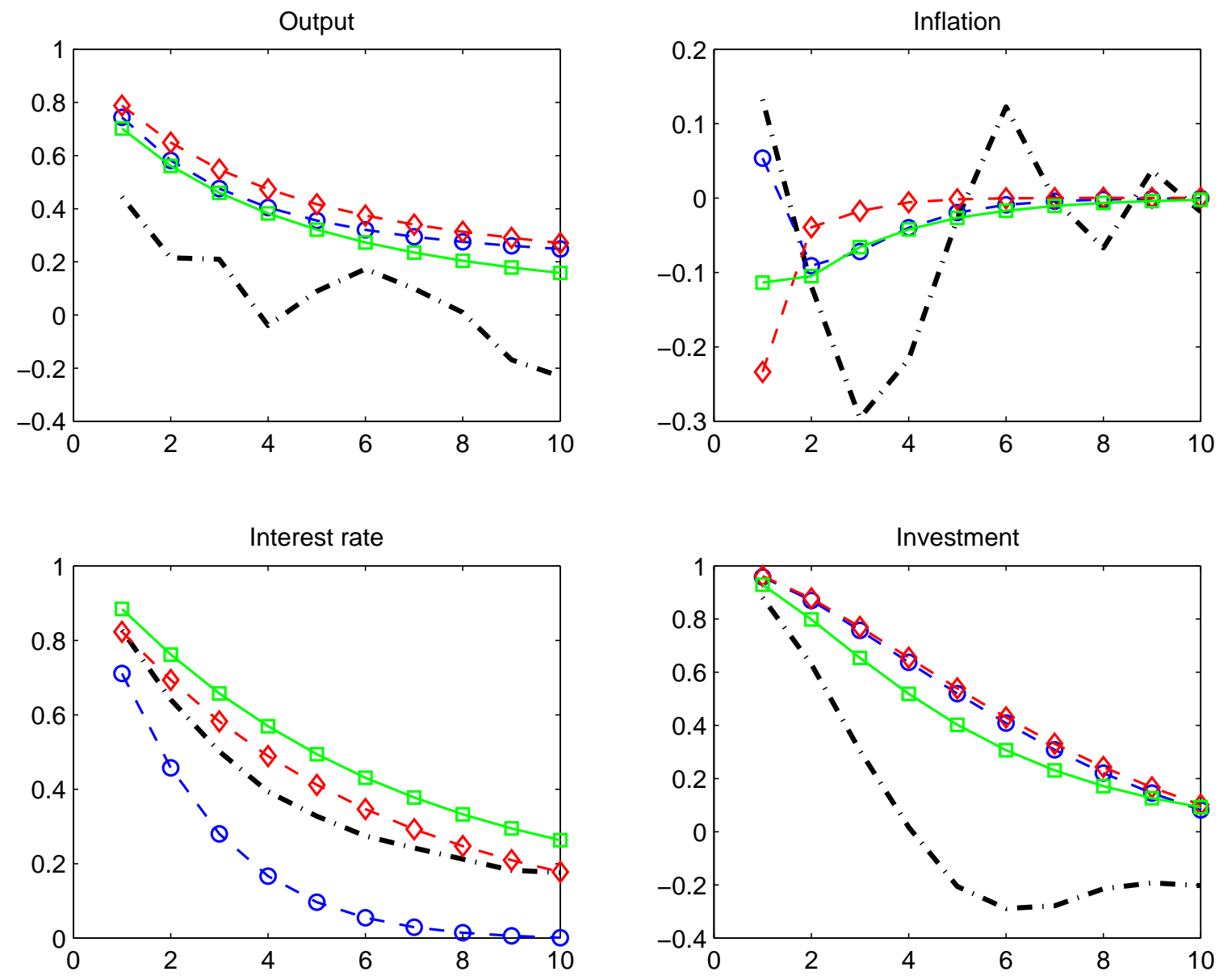

- ' - ' data $-\ominus-$ NK Model $-\ominus-$ NK Model with FA — $\square$ 2-sector NK Model

Figure 9: Autocorrelations of Observables in the Actual Data and in the Estimated MOdels 